\title{
Distribution of Dopamine Immunoreactivity in the Rat, Cat, and Monkey Spinal Cord
}

\author{
J.C. HOLSTEGE, H. VAN DIJKEN, R.M. BUIJS, H. GOEDKNEGT, T. GOSENS, \\ AND C.M.H. BONGERS \\ Department of Anatomy, Erasmus University Medical School, 3000 DR Rotterdam, \\ The Netherlands (J.C.H., H.V.D., H.G., T.G., C.M.H.B.), and Institute for Brain Research \\ (R.M.B.), $1105 \mathrm{AZ}$ Amsterdam, The Netherlands
}

\begin{abstract}
In the present study, the distribution of dopamine (DA) was identified light microscopically in all segments of the rat, cat, and monkey spinal cord by using immunocytochemistry with antibodies directed against dopamine. Only fibers and (presumed) terminals were found to be immunoreactive for DA. Strongest DA labeling was present in the sympathetic intermediolateral cell column (IML). Strong DA labeling, consisting of many varicose fibers, was found in all laminae of the dorsal horn, including the central canal area (region X), but with the exception of the substantia gelatinosa, which was only sparsely labeled, especially in rat and monkey. In the motoneuronal cell groups DA labeling was also strong and showed a fine granular appearance. The sexually dimorphic cremaster nucleus and Onuf's nucleus (or its homologue) showed a much stronger labeling than the surrounding somatic motoneurons. In the parasympathetic area at sacral levels, labeling was moderate. The remaining areas, like the intermediate zone (laminae VI-VIII), were only sparsely innervated. The dorsal nucleus (column of Clarke) showed the fewest DA fibers, as did the central cervical nucleus, suggesting that cerebellar projecting cells were avoided by the DA projection. In all species, the descending fibers were located mostly in the dorsolateral funiculus, but laminae I and III also contained many rostrocaudally oriented fibers. It is concluded that DA is widely distributed within the spinal cord, with few differences between species, emphasizing that DA plays an important role as one of the monoamines that influences sensory input as well as autonomic and motor output at the spinal level. 1996 Wiley-Liss, Inc.
\end{abstract}

Indexing terms: dorsal horn, motoneuron, parasympathetic, sexually dimorphic nuclei, sympathetic

The existence of dopamine (DA, also known as oxytyramine or hydroxytyramine) in the brain was already known for some time (Blaschko, 1939), when it was recognized in the late 1950's that DA could function as an independent catecholamine transmitter (Montagu, 1957), possibly involved in Parkinson disease (Carlsson, 1959). Initially, DA was localized with the Falck-Hillarp formaldehyde histofluorescence technique, which was used by Dahlström and Fuxe (1964) for a detailed mapping of DA cell groups, fibers and terminals in the brain. With respect to the spinal cord, they concluded that, in contrast to noradrenaline (NA), DA was not present. However, with the histofluorescence technique (and its modifications) it is difficult to differentiate between noradrenergic and dopaminergic fibers and terminals, especially in areas where they are intermingled. This problem does not occur with biochemical techniques, which showed that after transecting the rat spinal cord (Magnusson, 1973) or traumatizing the spinal cord of dogs (Hedeman et al., 1974), the NA concentration caudal to the lesion declined at a different rate than the DA concentration. These findings suggested a transmitter role for DA, independent from NA, even though the DA concentration in the spinal cord is five to ten times lower than the concentration of NA (Hedeman et al., 1974; Commissiong et al., 1978; Karoum et al., 1981; Basbaum et al., 1987). Furthermore, destruction of the locus coeruleus led to a decrease of the NA concentration in the spinal cord, although the concentration of DA remained unchanged (Commissiong et al., 1978). Similarly (partial) depletion of NA by 6-hydroxydopamine did not lead to a change in the DA concentration in the spinal cord (Mouchet et al., 1982). The use of neurotoxins to

\section{Accepted August 13, 1996}

Address correspondence and reprint requests to Dr. J. C. Holstege, Department of Anatomy, Erasmus University Medical School, P.O. Box 1738, 3000 DR Rotterdam, The Netherlands. E-mail: holstege@anat.fgg.eur.nl 
deplete NA made it also possible to identify DA containing structures with the histofluorescence technique, since the labelling observed after such treatment could only be attributed to the presence of DA. By using this approach, it was found (Skagerberg et al., 1982) that in the spinal cord, DA was present only in fibers and varicosities, located mainly in the dorsal horn, the area around the central canal and in the IML, with only a few scattered fibers in the ventral horn. The existence of a DA projection to the spinal cord, separate from NA, was also suggested by experiments in rat, which combined the retrograde transport of a fluorescent tracer with histofluorescence (Björklund and Skagerberg, 1979) or tyrosine hydroxylase (TH) immunocytochemistry (Hökfelt et al., 1979). These experiments showed the existence of a catecholaminergic projection from the diencephalon to the spinal cord (diencephalospinal tract), originating in the A11 cell group and, in the rabbit, the A.13 cell group (Blessing and Chalmers, 1979). The existence of a DA projection from the paraventricular hypothalamic nucleus to the spinal cord has also been suggested (Swanson et al., 1981), but this was not confirmed in later studies (Skagerberg and Lindvall, 1985; Skagerberg et al., 1988). Since neurons in the A11 cell group do not contain dopamine- $\beta$-hydroxylase (Swanson and Hartman, 1975), the enzyme synthesizing NA from $\mathrm{DA}$, they were considered as dopaminergic. Further investigations on the diencephalospinal system (Skagerberg and Lindvall, 1985) showed that relatively few cells in the A11 cell group provided the DA innervation for the entire spinal cord through a highly collateralized system. Thus, the presence of DA as a transmitter in the spinal cord and the existence of a DA projection to the spinal cord originating in the hypothalamus are now well established.

For an analysis of the laminar distribution of the DA fibers within the spinal cord, TH immunocytochemistry was used after destroying the NA terminals with 6-hydroxydopamine treatment (Dietl et al., 1985). This study showed the highest density of TH-immunoreactive DA fibers in laminae III, IV, X, and the thoracic IML, with few fibers elsewhere in the spinal cord. The identification of DA by using high performance liquid chromatography (HPLC) with electrochemical detection applied to microdissected spinal cord areas (Basbaum et al., 1987) showed that highest levels of DA were present in the IML, the dorsal horn and the central canal region with somewhat lower levels in laminae VI and VII. A limited, but consistent amount of DA was also found in the motoneuronal cell groups, indicating a direct DA innervation of spinal motoneurons. The latter finding confirmed the results obtained with specific uptake of ${ }^{3} \mathrm{H}-\mathrm{DA}$, which showed radioactively labeled terminals in the dorsal as well as the ventral horn (Kondo et al., 1985). When it became possible to produce specific antibodies directed against small transmitter molecules (Storm-Mathisen et al., 1983), including DA and NA (Geffard et al., 1984, 1986; Buijs et al., 1989), these transmitters could be directly visualized by immunocytochemistry. With this technique, the presence of DA fibers and terminals in the spinal cord was confirmed (Yoshida and Tanaka, 1988; Shirouzu et al., 1990; Mouchet et al., 1992; Ridet et al., 1992). However, some uncertainty remained with respect to the intensity of the DA innervation of the motoneuronal cell groups. The present study was undertaken to investigate in detail the localization of DA in all spinal segments of the rat, cat and monkey spinal cord by using immunocytochemistry with highly specific antibodies against DA. We found DA immunoreactivity in all laminae of the spinal cord, without major differences between species. Labeling was concentrated in the dorsal horn and the IML. In addition, we found many lightly stained varicosities in the motoneuronal cell groups, confirming the existence of a prominent DA projection to spinal motoneurons.

\section{MATERIALS AND METHODS}

A detailed analysis was performed on material obtained from adult male Wistar rats, three female cats, one female monkey (Macaca fasicularis) and one male monkey ( $\mathrm{Ma}$ caca arctoides). All the animals were obtained through the institutional animals facility, housed and handled according to national guidelines, supervised by an institutional animal care and usage committee. The male monkey was bred by a pharmaceutical company and had not been involved in any previous testing. The female monkey, which had been obtained from an institutional research facility, had been involved in behavioural experiments, without any known pharmacological testing. They were kept in our institutional facility for at least 1 year in good health. The other animals were obtained from approved breeders through the institutional experimental animal facility. Before perfusion, the animals were deeply anaesthetized with pentobarbital $(70 \mathrm{mg} / \mathrm{kg})$ intraperitoneally.

\section{Immunocytochemical procedures}

The animals were perfused transcardially with $50 \mathrm{ml}$ (rats), $150 \mathrm{ml}$ (cats) or $500 \mathrm{ml}$ (monkeys) of saline containing $10 \mathrm{mM}$ ascorbic acid, $\mathrm{pH} 7.4$, followed by 1 liter (rats), 2.5 liters (cats), or 4 liters (monkeys) of $10 \mathrm{mM}$ ascorbic acid in $0.05 \mathrm{M}$ acetate buffer, $\mathrm{pH} 4.0$ (AAAB), containing $5 \%$ glutaraldehyde. After perfusion, the spinal cords were dissected and all the spinal segments were identified and cut with a razor blade. They were kept overnight at $4^{\circ} \mathrm{C}$ in $\mathrm{AAAB}$, containing $30 \%$ sucrose. The following days, $30 \mu \mathrm{m}$ sections were obtained on a sliding freezing microtome from all cervical, lumbar, and sacral, as well as half the thoracic and the rostral coccygeal spinal segments. The free floating sections were collected in Tris-buffered saline, $\mathrm{pH}$ 7.4 , containing $10 \mathrm{mM}$ ascorbic acid (TBSA). Some spinal cord segments were cut in horizontal or sagittal sections. The free floating sections were rinsed in TBSA and kept for several days in the same liquid at $4^{\circ} \mathrm{C}$. Next they were treated with TBSA, containing $1 \%$ borohydrate $(\mathrm{NaBH} 4)$ for 30 minutes at room temperature. They were then rinsed several times in TBSA and incubated overnight at $4^{\circ} \mathrm{C}$ with a polyclonal DA antibody from rabbit ("Jannes") (Buijs et al., 1984; Voorn and Buijs, 1987) diluted 1:4,000 in Trisbuffered saline, $\mathrm{pH} 7.4$ (TBS), containing $0.5 \%$ Triton $\mathrm{X}-100$ and $10 \mathrm{mM}$ ascorbic acid. In rat and cat, several sections were also treated with a different DA antibody (Steinbusch and Tilders, 1987; Steinbusch et al., 1991) (SanBio B.V., Uden), diluted $1: 2,000$ in [Tris-buffered saline (TBSA)]. After the primary DA antibody, the sections were rinsed thoroughly with TBS and a goat anti-rabbit (GAR) antibody ("Betsy," diluted 1:100, 1 hour incubation) was applied. Subsequently the sections were rinsed with TBS and incubated with a rabbit peroxidase antiperoxidase (PAP) complex (Nordic, 1:1,000, 1 hour), rinsed in TBS followed by phosphate buffer $(0.1 \mathrm{M}, \mathrm{pH}$ 7.4). These incubations were performed at room temperature. Then the sections were reacted with $0.05 \% 3,3^{\prime}$-diaminobenzi- 
dine in the presence of $0.01 \%$ hydrogen peroxide in phosphate buffer $(0.1 \mathrm{M}, \mathrm{pH} 7.4)$. After rinsing in phosphate buffer, the sections were mounted onto glass slides with a chromealum-gelatine solution, and some were subsequently counterstained with $0.05 \%$ thionin. Finally, all sections were dehydrated, coverslipped and examined with bright and darkfield illumination. As a control, some of the sections were processed after substitution of the primary antiserum with TBS. This resulted in no contrast staining.

\section{DSP-4 experiments}

In order to deplete NA in the spinal dorsal horn, four rats received an intraperitoneal injection $(50 \mathrm{mg} / \mathrm{kg})$ of $N-(2-$ chloroethyl)- $N$-ethyl-2-bromobenzylamine (DSP-4) (Jonsson, 1983), and two rats received an intraperitoneal saline injection. After a period of 2 weeks, the rats were deeply anaesthetized and perfused for DA immunocytochemistry as described above. Alternate $30 \mu \mathrm{m}$ frozen sections were processed for either DA or dopamine- $\beta$-hydroxylase $(\mathrm{DBH})$ immunocytochemistry. For DA immunocytochemistry the same procedure was used as described above except for the GAR antibody (Vector, 1:200, 1 hour incubation) and the rabbit-PAP complex (Nordic, 1:800, 1 hour incubation). For DBH immunocytochemistry the sections were preincubated in a solution of $5 \%$ normal goat serum (NGS) in phosphate buffer ( $\mathrm{PB} ; 0.1 \mathrm{M}, \mathrm{pH} 7.4)$ containing $0.9 \% \mathrm{NaCl}$ and $0.3 \%$ Triton $\mathrm{X}-100$ for 90 minutes. Next they were incubated for $24-48$ hours at $4^{\circ} \mathrm{C}$ with rabbit anti-DBH (Eugene Tech; 1:750) in 0.1 M PBS ( $\mathrm{pH} 7.4$ ) containing $0.3 \%$ Triton-X100 and $2 \%$ NGS. Hereafter, the sections were rinsed and incubated (1-2 hours) with biotinylated GAR (Vector; 1:200). After a few rinses, biotin avidin complex (Vector) was applied (1-2 hours). Finally, the sections were reacted with 3,3'-diaminobenzidine in the presence of $0.01 \%$ hydrogen peroxide, rinsed several times in $\mathrm{PB}$, mounted on glass slides with chromealum, dehydrated, coverslipped, and examined with bright and darkfield illumination.

\section{RESULTS}

The distribution of DA immunoreactivity was examined light microscopically in transverse, horizontal, and sagittal sections from nearly all segments of the rat, cat, and monkey spinal cord (Figs. 1-11). DA immunoreactivity was present almost exclusively in fibers and (presumed) terminals. Labeled neuronal cell bodies were found in all species only in the rostral part of C1. Labeled neuronal cells (0-5 cells per section) were found in the ventrolateral funiculus and in the area immediately dorsal of the central canal. In all likelihood these cells represented the caudal extension of the A1 and A2 cell group, respectively, as described by Dahlström and Fuxe (1964) in the lower medulla. Labeled neuronal cell bodies were never found in other areas of the spinal cord. DA fibers and varicosities were found in all laminae of the spinal grey matter at all spinal levels, but with considerable differences in regional density.

The following detailed descriptions were made from sections treated with the "Jannes" DA antibody for which the method was optimized. An identical labeling pattern was obtained by using the Sanbio DA antibody. The distribution of the DA immunoreactivity will be described separately for the dorsal horn, the ventral horn and various "specialized areas" in the spinal cord. In addition, the location of the descending fibers in the white and grey matter will be described.

\section{Dorsal horn}

Within the dorsal horn of the rat, cat and monkey spinal cord, DA immunoreactivity was found in all laminae (Figs. $1-7,10)$. As a rule, labeling was moderate in lamina I, sparse (rat and monkey) to moderate (cat) in lamina II (substantia gelatinosa) and strong in laminae III-V. In lamina I of rat and monkey there were many short fibers with varicosities and occasional patches of labeling consisting of many small-caliber fibers and varicosities, which sometimes seemed to exceed the width of lamina I in dorsal or ventral direction. Only a few varicose fibers were traversing lamina II. In the cat the difference in labeling intensity between laminae I and II was less pronounced. In laminae III, IV, and V, including the neuropil of the lateral reticular part of these laminae, thick fibers with clear varicosities formed a dense network. Horizontal and parasagittal sections (Fig. 11) showed that most fibers in lamina III, as well as those in laminae I and II, were oriented predominantly in a rostrocaudal direction, but in lamina $\mathrm{V}$ and, to a lesser extent, in lamina IV, this rostrocaudal orientation of the fibers was not observed; instead they were oriented more randomly. The area around the central canal contained only a few rostrocaudally oriented fibers. In transverse sections it appeared that many dorsoventrally oriented fibers at the medial border of the dorsal horn terminated in the central canal region or crossed to the other side, mostly into the dorsal grey matter. In addition to these general aspects of DA immunoreactivity in the dorsal horn, there were also differences between species as described below.

Rat dorsal horn. In rat (Figs. 1, 6, 7, 10), labeling was strongest in lamina III and slightly less prominent in laminae IV and V. In lamina I the intensity of the labeling was clearly less as compared to the deeper laminae. The lowest amount of labeling was seen in lamina II where immunoreactivity was almost absent, apart from some traversing fibers, which ran mostly in a rostrocaudal direction (Fig. 11). At the lower cervical as well as the lower lumbar levels, there was less labeling in the medial part of laminae III-V as compared to the lateral part (Fig. 10). The overall labeling of the dorsal horn was less dense in the lumbosacral cord than in the cervical cord, although the general pattern of the labeling was the same at both levels. The lateral spinal nucleus (not indicated in Fig. 1) was moderately innervated throughout the spinal cord.

Cat dorsal horn. In cat (Figs. 2, 4), the differences in labeling intensity between laminae was much less as compared to the rat. Strongest labeling was found not only in laminae III-V, but also in lamina I. Lamina II was moderately innervated. Differences in labeling between the medial and lateral part of laminae III-V at low cervical levels were less pronounced than in rat and monkey. At thoracic levels, the overall labeling intensity became less than at cervical levels and labeling in lamina II was sparse, containing mostly rostrocaudally oriented fibers. Going further caudally to lumbar levels, the labeling intensity increased again, being strongest at L7. However, like in rat, labeling was still less intense as compared to the cervical cord.

Monkey dorsal horn. In monkey dorsal horn (Figs. 3, 5 -top) the overall labeling intensity was somewhat less than in the rat and cat. In the Macaca fasicularis, at cervical levels, lamina I was moderately labeled with fine-caliber fibers, and in laminae III and IV several thick strongly 


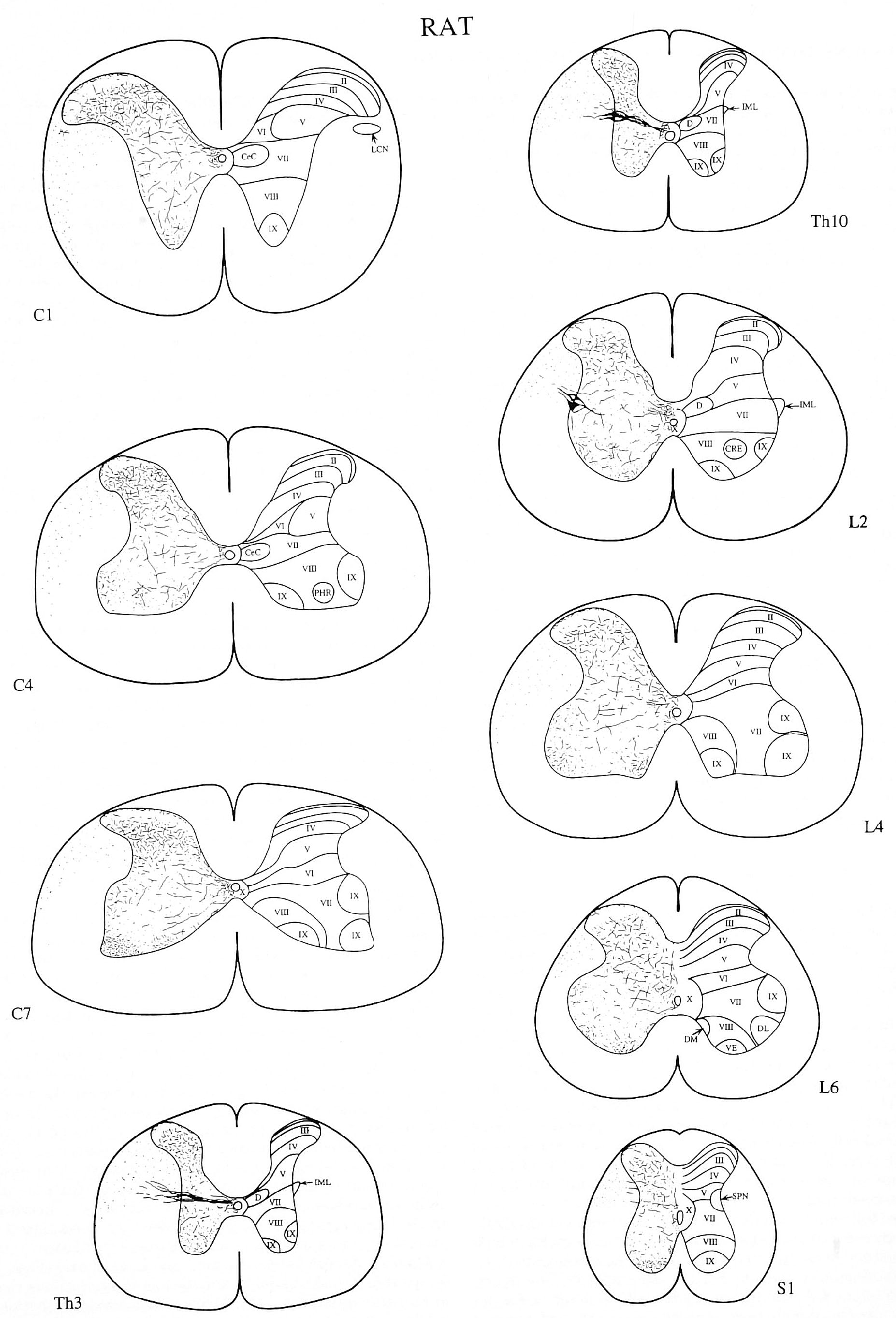

Fig. 1. Schematic representation of the dopamine (DA) innervation in selected segments of the rat spinal cord. For details see text. $\mathrm{CeC}$, central cervical nucleus; $\mathrm{CRE}$, cremaster nucleus; $\mathrm{D}$, dorsal nucleus (column of Clarke); For details see texal nucleus; DM, dorsomedial nucleus; IML, intermediolateral nucleus; LCN, lateral cervical nucleus; PHR, nucleus of the phrenic nerve; SPN, sacral parasympathetic nucleus; VE, ventral nucleus. 
CAT
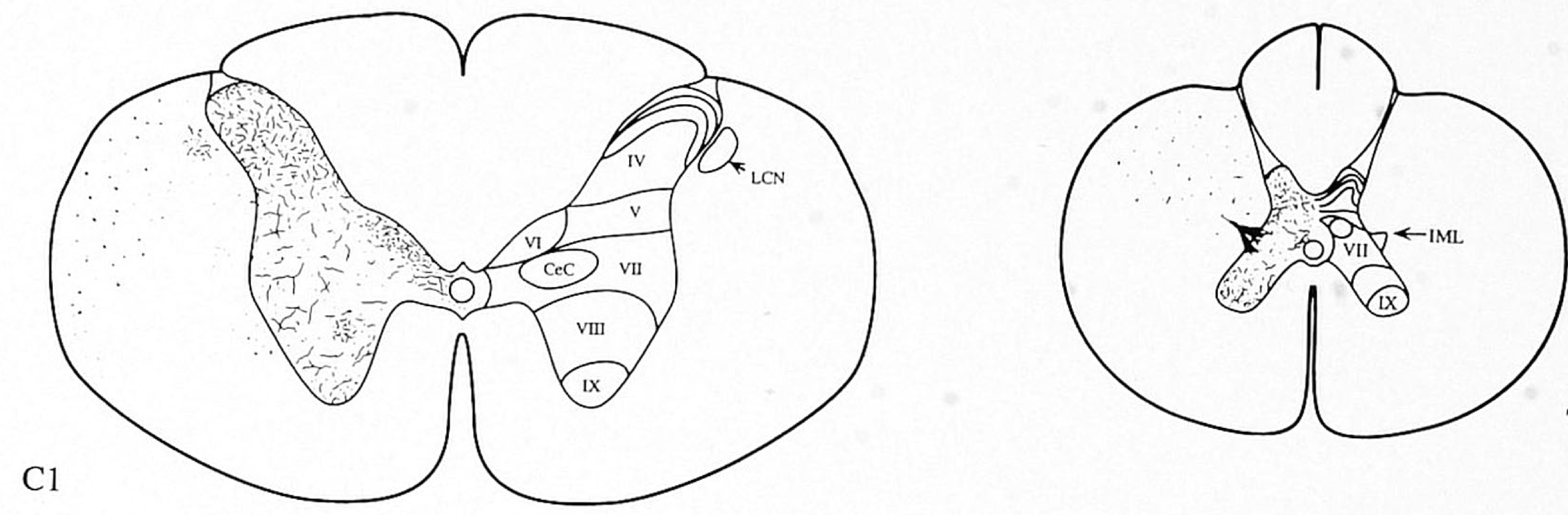

Th10
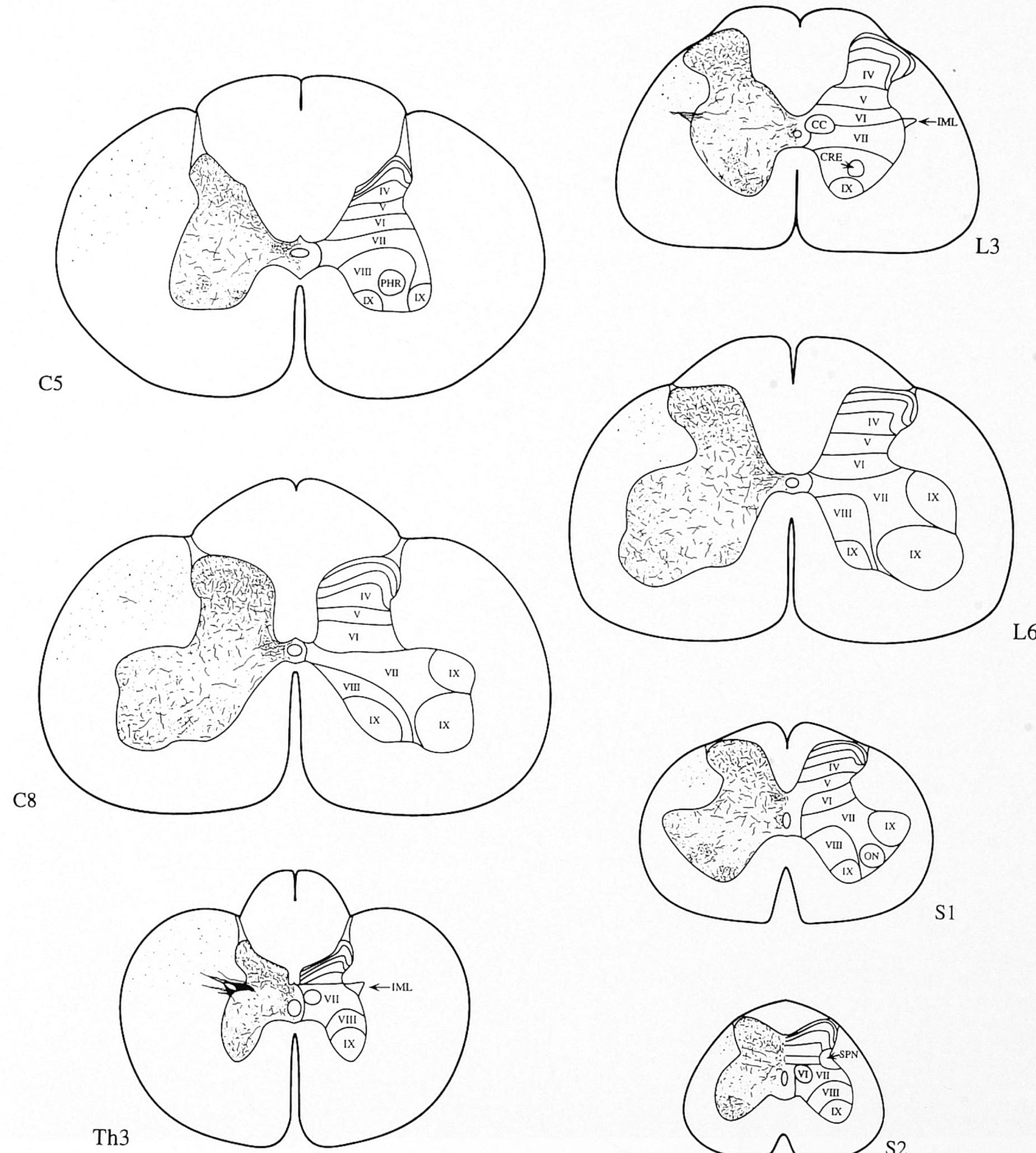

Fig. 2. Schematic representation of the DA innervation in selected segments of the cat spinal cord. For details see text. CC, column of Clarke (dorsal nucleus); ON, Onuf's nucleus; for other abbreviations see Figure 1. 


\section{MONKEY}
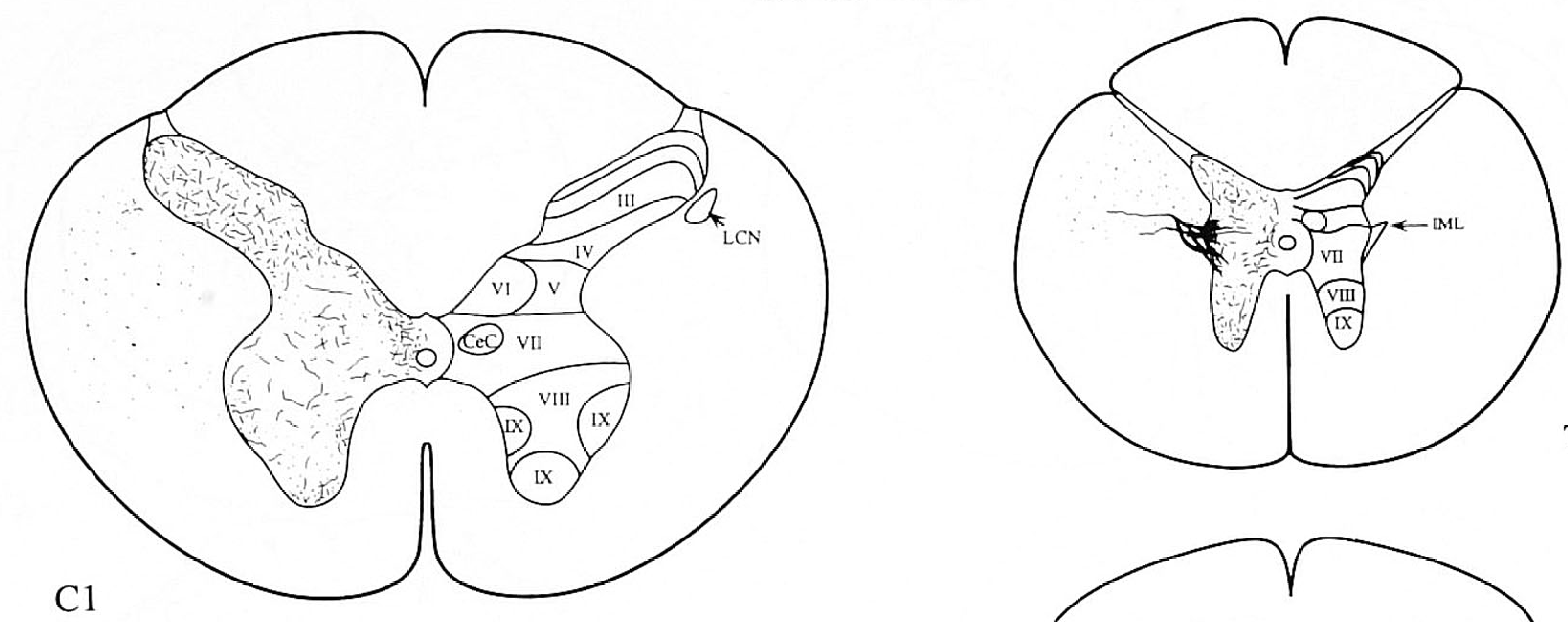

Th10
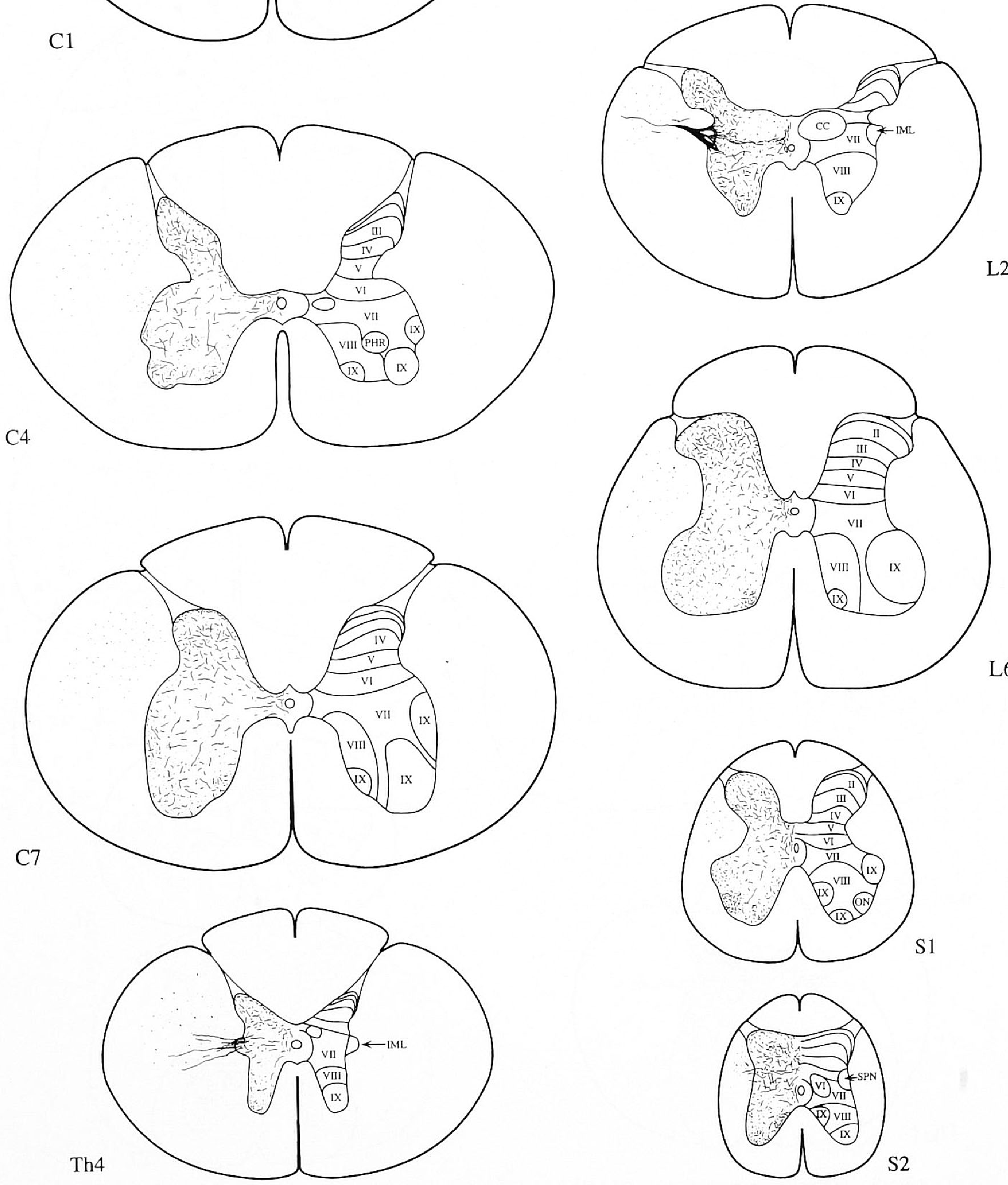

Fig. 3. Schematic representation of the DA innervation in selected segments of the monkey spinal cord. For details see text. For abbreviations, see Figure 2. 


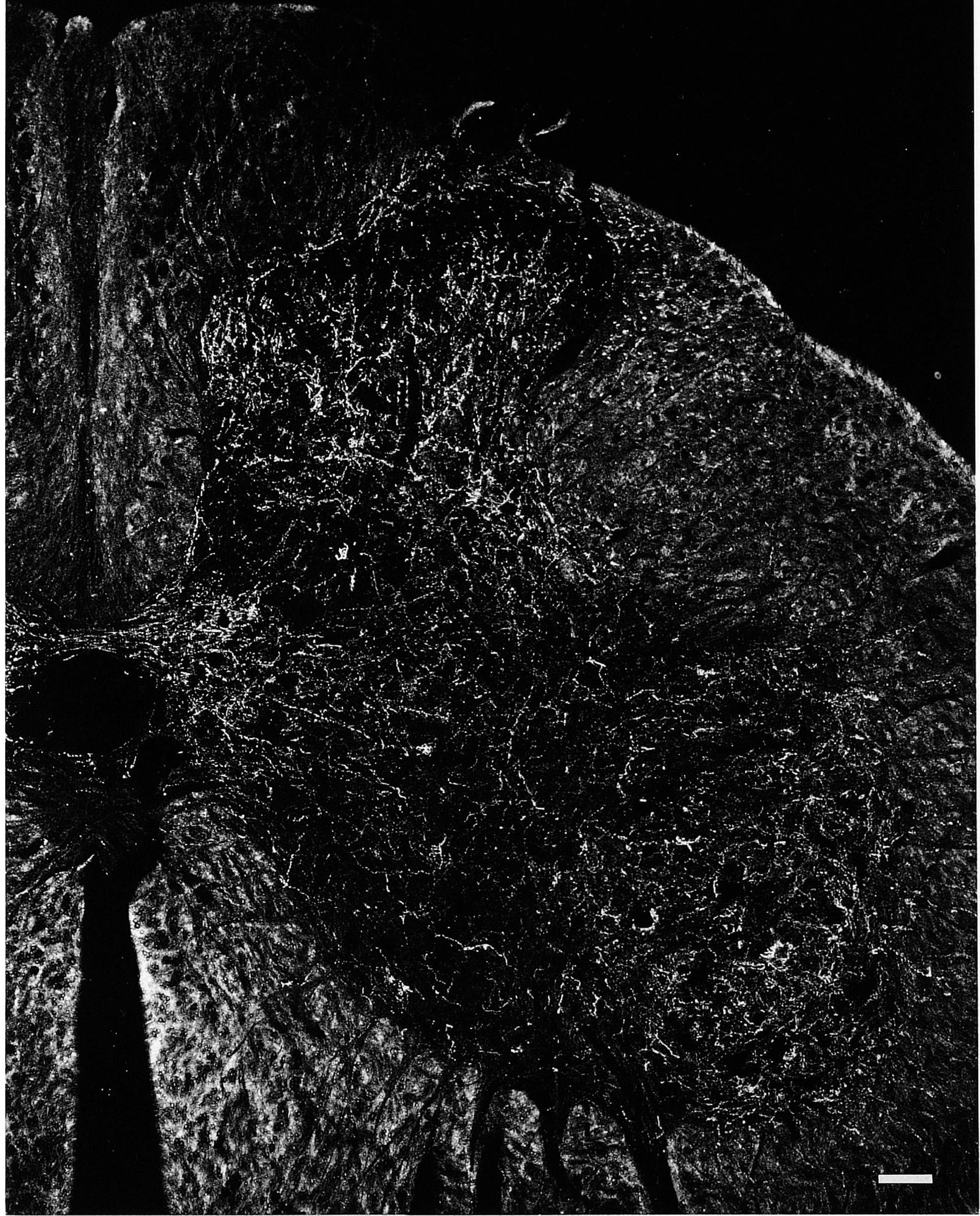

Fig. 4. Photomicrograph with darkfield illumination of a section from the cat L6 segment showing DA-immunoreactive fibers and varicosities. Note the difference in the type of labeling in the dorsal and ventral horn, the sparse labeling in the substantia gelatinosa (lamina II, see Fig. 2) and in the ventral horn intermediate zone (laminae VII and VIII, see Fig. 2). Also note the descending fibers in the dorsolateral funiculus close to the dorsal horn (see also Fig. 2). Scale bar $=120 \mu \mathrm{m}$. 

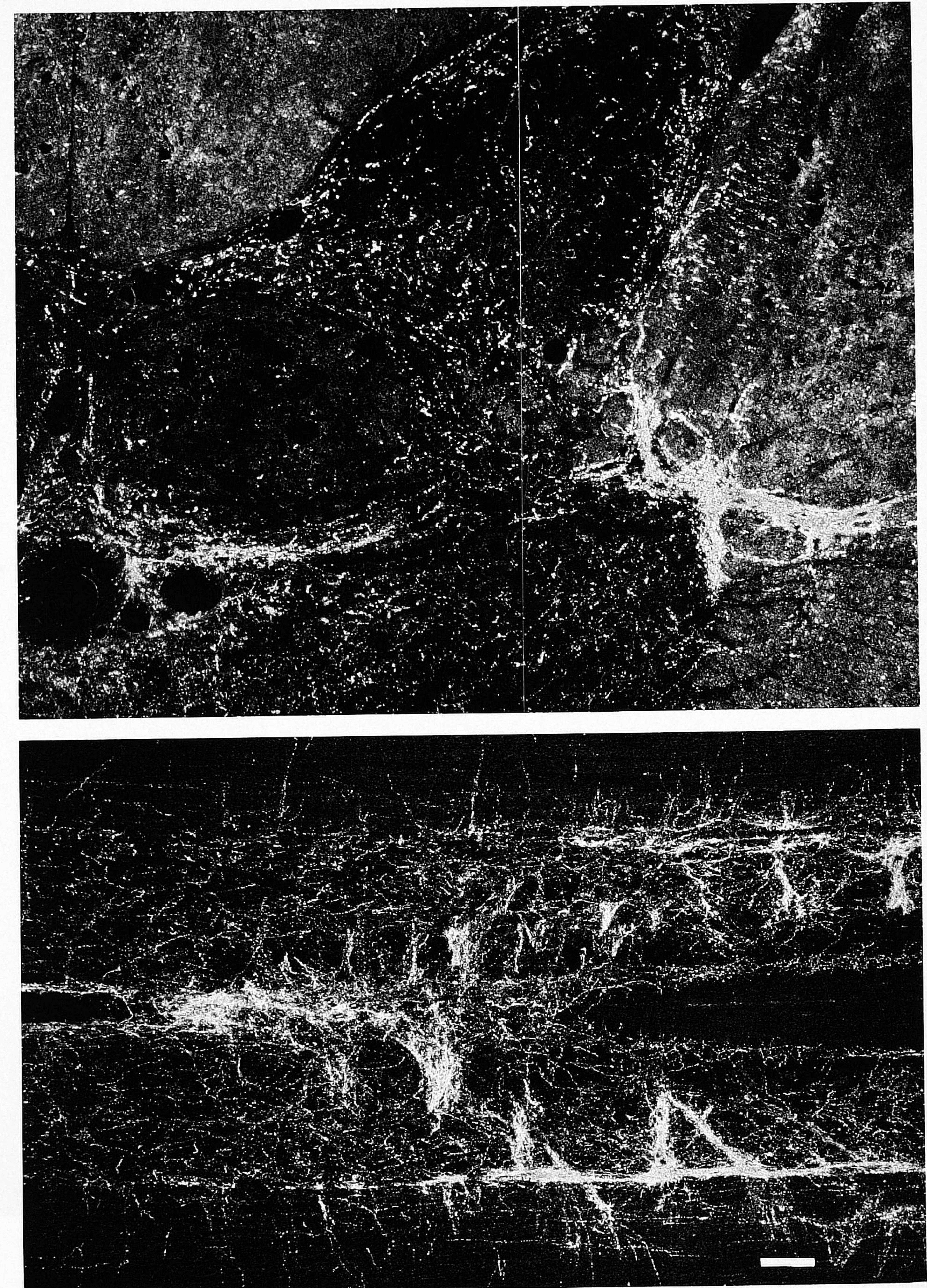
labeled fibers were present, mainly in the medial part of this area. Lamina II was sparsely labeled, containing a few rostrocaudally oriented fibers. At thoracic levels, overall labeling intensity was decreased, with very few labeled fibers in lamina II. Going further caudally to lumbosacral levels, the intensity of the labeling increased again, but lamina II remained sparsely innervated. The same pattern, including a sparsely innervated lamina II was also found at sacral levels. In the Macaca arctoides the labeling pattern was rather different from the other monkey because of a sparse-to-moderate labeling of laminae III and IV; lamina I was strongly labeled, and labeling in lamina II was sparse (Fig. 5-top). This typical pattern of dorsal horn labeling was especially apparent at cervical levels and was not seen in rats and cats or in the other monkey.

\section{Ventral horn}

The DA immunoreactivity in the ventral horn (Figs. 1-4, $6-9,11$ ) had a very different appearance as compared to the dorsal horn. For a major part this difference was due to the type of innervation of the motoneuronal cell groups. This area (lamina IX) received a dense innervation of immunoreactive varicosities, many of which appeared to be smaller than in other laminae of the spinal cord. In addition, intervaricose segments were less pronounced, giving the labeling of the motoneuronal cell groups a fine granular (punctate) appearance, especially at lower magnifications (compare Figs. 4, 6, 8 with Fig. 7). Interestingly, this type of labeling was found in transverse, horizontal, and sagittal sections, indicating that the innervation pattern is organized without a predominant orientation, except for some "specialized areas" (see below). In all species a very strong labeling of the motoneuronal cell groups innervating the tail muscles was observed at the sacral (Fig. 6) and coccygeal segments. This labeling was also of a fine granular appearance. In the intermediate zone (laminae VII and VIII) labeling was sparse with only a few traversing fibers.

Rat ventral horn. In the rat ventral horn (Figs. 1, 6, 7, 9) DA immunoreactivity generally appeared as indicated above. With respect to regional differences, there was a slightly increased labeling in the ventrolateral group of motoneurons mainly at the $\mathrm{C} 7$ segment (Matsushita and Ueyama, 1973). DA immunoreactivity in the medial and lateral motoneuronal cell groups was equally strong both at low cervical and low lumbar spinal levels. At caudal thoracic and especially at lumbar levels, there was a slight increase in varicose fibers in the motoneuronal cell groups and, as a

Fig. 5. Top: Photomicrograph with darkfield illumination of a section from the monkey L2 segment, which shows DA-immunoreactive fibers and varicosities. Note only very sparse labeling in the dorsal nucleus (column of Clarke, see Fig. 3 ) and very strong labeling in the IML nucleus. Scale bar $=60 \mu \mathrm{m}$. Bottom: Photomicrograph with darkfield illumination of a horizontal section from the rat T6-T7 segment, which shows DA-immunoreactive fibers and varicosities. Note in the midline on the left the central canal and on the right the dorsal funiculus, indicating that the horizontal section is oriented slightly dorsoventrally. This makes it possible to see the strong labeling in the IML nucleus on the right, the labeling in the intercalatus nuclei in the middle and the central autonomic nuclei on the left. Also note that neurons of the dorsal nucleus (right, close to the dorsal funiculus, relatively small at this level) are avoided by the DA fibers. In the lateral funiculus (located along the entire length of the top and the bottom of the micrograph) some rostrocaudally oriented fibers can be seen as well as laterally running fibers, which probably innervate laterally running dendrites of IML neurons. Scale bar $=140 \mu \mathrm{m}$. result, the fine granular appearance of the DA immunoreactivity became less conspicuous.

Cat ventral horn. In cat (Figs. 2, 4), as in rat, DA immunoreactivity was much stronger in the motoneuronal cell groups as compared to the intermediate zone. However, the differences in the type of labeling between the two areas, as found in rat, was much less apparent in cat. This was due on the one hand to an increased number of labeled fine-caliber fibers and varicosities in the intermediate zone; on the other hand, the number of labeled large varicosities and fibers in the motoneuronal cell groups was increased. At low cervical levels there was especially strong labeling in the ventral motor nucleus (Matsushita and Ueyama, 1973), at the C7-C8 segments. At thoracic and high lumbar levels the intermediate zone was almost devoid of labeling, but labeling of the motoneuronal cell groups remained strong.

Monkey ventral horn. In the monkey ventral horn (Figs. 3,8 ) the fine granular aspect of the DA immunoreactivity in the motoneuronal cell groups was in sharp contrast to the thick varicose fibers in the dorsal horn. Thick varicose fibers were also found in the intermediate zone, but here the number of fibers and varicosities was much less. The difference in density and intensity of the labeling between the intermediate zone and the motoneuronal cell groups became less apparent at the cervical and lumbar enlargements because of a stronger labeling in the intermediate zone. Also in these areas the labeling in the motoneuronal cell groups was somewhat stronger.

\section{Specialized areas}

Central cervical nucleus. The central cervical nucleus, just dorsolateral to the central canal, is present mainly at high cervical levels, but is often difficult to delineate. It received a very sparse DA innervation, consisting mainly of a few fibers traversing the nucleus.

Lateral cervical nucleus. The lateral cervical nucleus, which is located at the segments $\mathrm{C} 1-\mathrm{C} 3$, is most prominent in the cat and monkey. It received a moderate innervation with DA fibers and varicosities.

Region around the central canal. The region around the central canal, also referred to as lamina X, received a strong DA innervation, consisting of both thick- and finecaliber fibers and varicosities (Figs. 1-6). This innervation was limited to the region directly surrounding the central canal and a somewhat wider area extending bilaterally in a dorsolateral direction. This area also contained several crossing DA fibers, which were located in the dorsal grey commissure and appeared to run toward the contralateral dorsal horn rather than the ventral horn.

Phrenic nucleus. In transverse sections of the C4-C6 segments, a characteristic group of motoneurons, corresponding to the nucleus of the phrenic nerve (Kuzuhara and Chou, 1980), was observed ventromedially in the ventral horn (Figs. 1-3, 9). DA immunoreactivity in the phrenic nucleus showed a fine granular aspect, similar to that of surrounding motoneurons. In longitudinal and sagittal sections the phrenic motoneurons were easily distinguished by their longitudinally organized dendrites. In contrast to the findings in the transverse sections, DA immunoreactivity was stronger in the area containing these longitudinal dendrites than in the surrounding neuropil (Fig. 9). It was, therefore, concluded that the DA labeling of the phrenic nucleus was somewhat stronger than the 


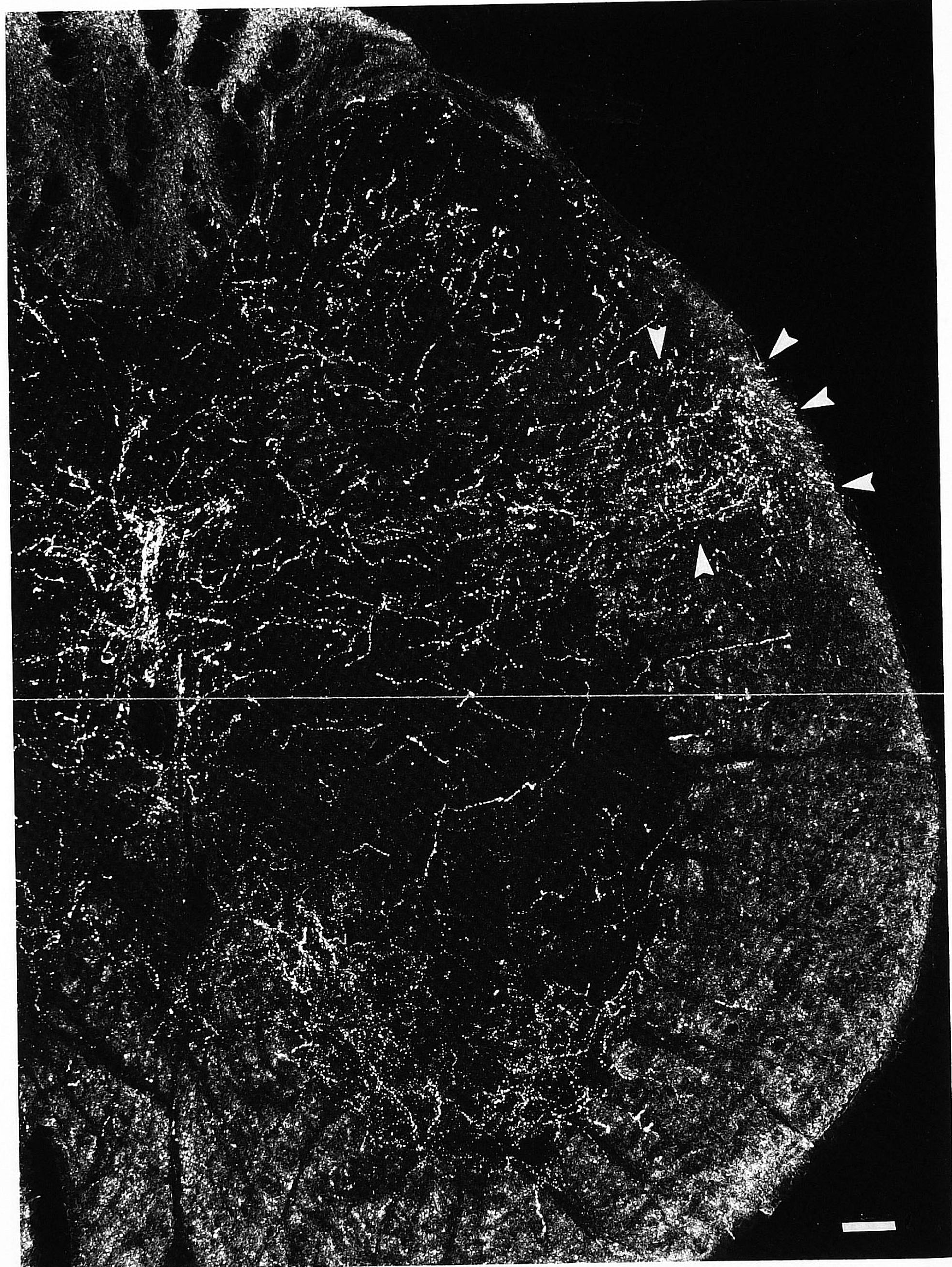

Fig. 6. Photomicrograph with darkfield illumination of a section from the rat $\mathrm{S} 1$ segment, which shows DA-immunoreactive fibers and varicosities. Note the labeling in the area of the parasympathetic preganglionic neurons just medial of the descending fibers in the dorsolateral funiculus (white arrowheads). Also note the strong, punctate labeling in the motoneuronal cell groups. Scale bar $=70 \mu \mathrm{m}$. 

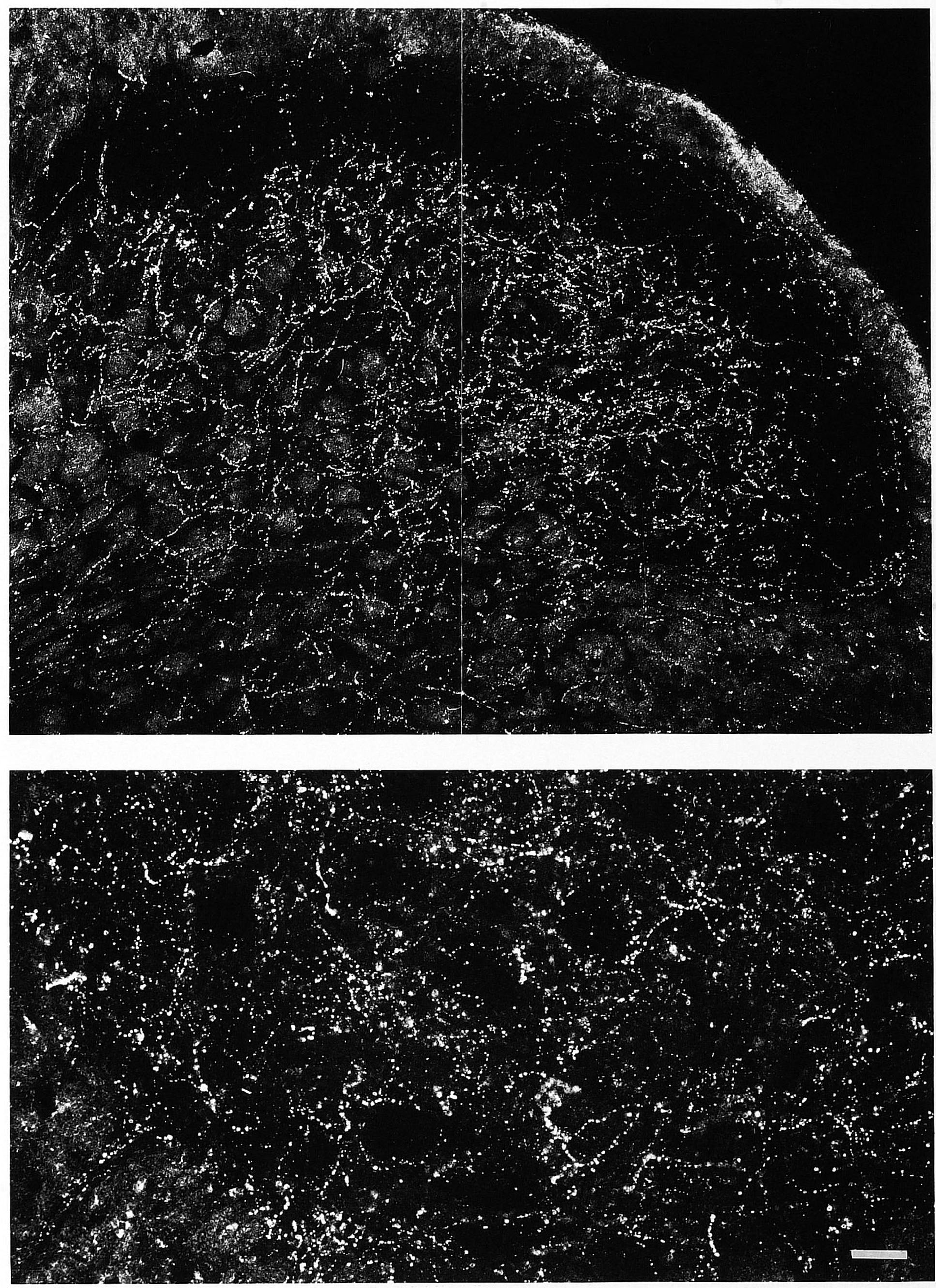

Fig. 7. Top: Photomicrograph with darkfield illumination of a section from the rat $\mathrm{C} 1$ segment, which shows DA-immunoreactive fibers and varicosities in the dorsal horn. Note the strong labeling in laminae III-V and the moderate labeling in lamina I, although labeling in lamina II (the substantia gelatinosa) is only sparse. See Figure 1 for laminar arrangement. Scale bar $=65 \mu \mathrm{m}$. Bottom: Photomicrograph with darkfield illumination of the motoneuronal cell groups from a section from the rat L5 segment, which shows DA-immunoreactive fibers and varicosities. Note the abundance of small varicosities, presumably terminals, with a paucity of intervaricose fibers, although the position of many varicosities suggests that they are interconnected. The motoneurons appear as "black holes." The ventral funiculus can be seen below and left. Scale bar $=35 \mu \mathrm{m}$. 


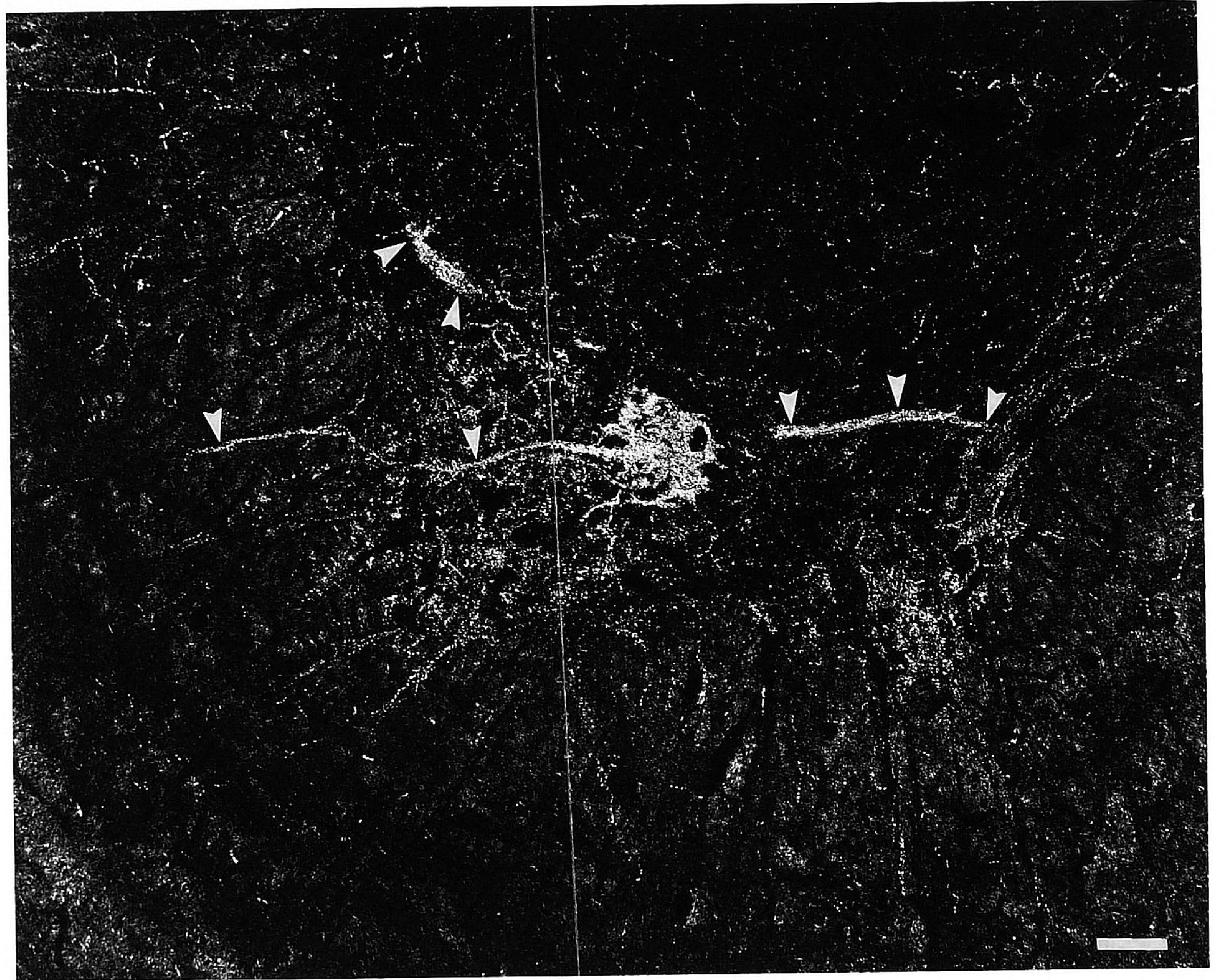

Fig. 8. Photomicrograph with darkfield illumination of a section from the monkey L3 segment, which shows a very large number of DA-immunoreactive fibers and varicosities around the motoneurons of the cremaster nucleus. Note that this strong innervation is also present along (presumed) dendritic bundles (white arrowheads) that radiate in ceveral directions. Also note the fine granular labeling in the other (medial and lateral) motoneuronal cell groups, but the intermediate zone is only sparsely innervated. Scale bar $=100 \mu \mathrm{m}$.

Dorsal nucleus (column of Clarke). The dorsal nucleus (also known as the column of Clarke) contains large cells, projecting to the cerebellum, and is located in segments T1 to L3 (Grant et al., 1982). DA innervation was nearly absent with only an occasional fiber and some terminallike structures (Fig. 5); most fibers seemed to avoid the nucleus.

Cremaster nucleus. The cremaster nucleus, a sexually dimorphic motor nucleus innervating the cremaster muscle, is located primarily in the segments L1 and L 2 and is most prominent in the male (Nagy and Senba, 1985). In the male arctoides monkey the cremaster nucleus received a very strong DA innervation (Fig. 8). In transverse sections the same strong innervation was sometimes seen in mediolaterally oriented dendritic bundles, which are known to belong to cremaster motoneurons (Fig. 8). In male rats and female cats, the cremaster nucleus also received a stronger innervation in comparison with surrounding motoneurons, but this labeling was less prominent than in the male monkey. 


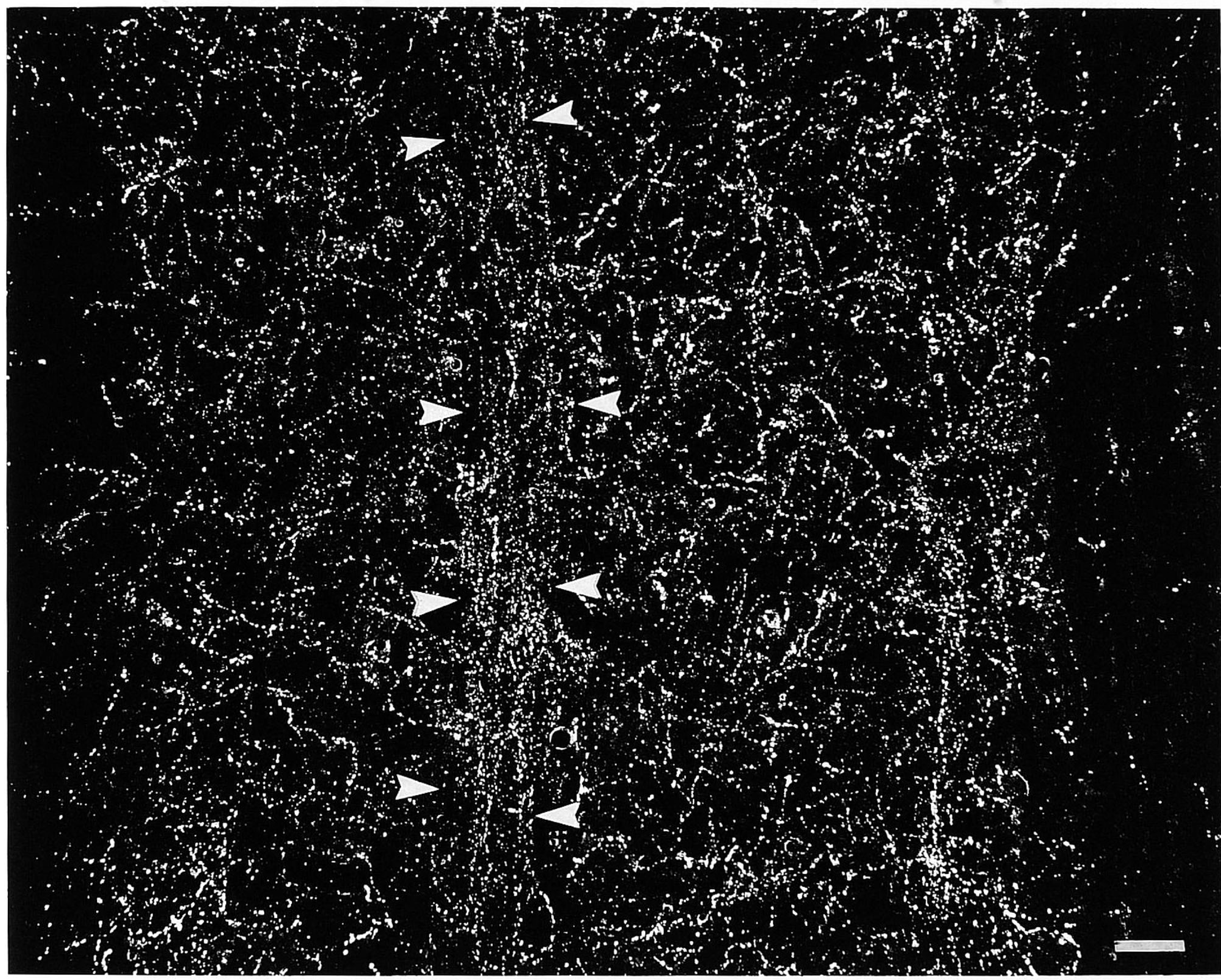

Fig. 9. Photomicrograph with darkfield illumination of a horizontal section through the ventral horn of the rat C4-C5 segments. The ventrolateral funiculus is located on the left side of the micrograph and the ventromedial funiculus is located on the right side. Note the longitudinally oriented DA labeling in the area of the phrenic nucleus

Lumbosacral motoneurons. The motoneurons, which innervate, through fibers in the pudendal nerve, the anal and urethral sphincter muscles, and related muscles, form a special group of motoneurons (Schrøder, 1980). They are somewhat smaller than the surrounding (somatic) motoneurons and they are sexually dimorphic (McKenna and Nadelhaft, 1986). In different species these motoneurons are located in different areas of the ventral horn. In rat two different groups can be distinguished, namely, the nucleus dorsomedialis (DM) (also known as the spinal nucleus of the bulbocavernosus, SNB) and nucleus dorso lateralis (DL) (Schrøder, 1980). In cat the DM and DL nuclei, as distinguished in the rat, are fused to form a ventrolaterally located nucleus, designated (like in man) as Onuf's nucleus (Sato et al., 1978; Ueyama et al., 1984). In monkey the organization is similar to the cat (Nakagawa, 1980). The DM and DL nuclei in the rat and Onuf's nuclei in the cat and monkey received a strong DA innervation, which was (white arrowheads), presumably alongside dendrites of phrenic motoneurons. Also note that the longitudinally oriented labeling appears somewhat stronger than the labeling in the surrounding neuropil. Scale bar $=55 \mu \mathrm{m}$

much stronger than dorsolaterally located motoneurons, which innervate muscles associated with the foot. Sometimes prominent dendritic bundles were seen radiating laterally and medially from Onuf's and DL nuclei and laterally from the DM nucleus. These bundles also received a strong DA innervation. The intensity of the labeling in the sexually dimorphic nuclei was similar to that of the tailmuscle motoneurons, which first appear ventromedially in the ventral horn, at the $\mathrm{S} 1$ segment. In addition, a ventral group of motoneurons, innervating the levator ani muscle, also received a strong DA innervation, similar to Onuf's nucleus.

Sacral parasympathetic area. The sacral parasympathetic area, located mainly in the segments S1-S4 (depending on species) contains the parasympathetic nucleus. This area showed a stronger DA innervation than the surrounding intermediate zone (Fig. 6), but it could not be determined whether the DA fibers terminated specifically on the preganglionic parasympathetic neurons. 

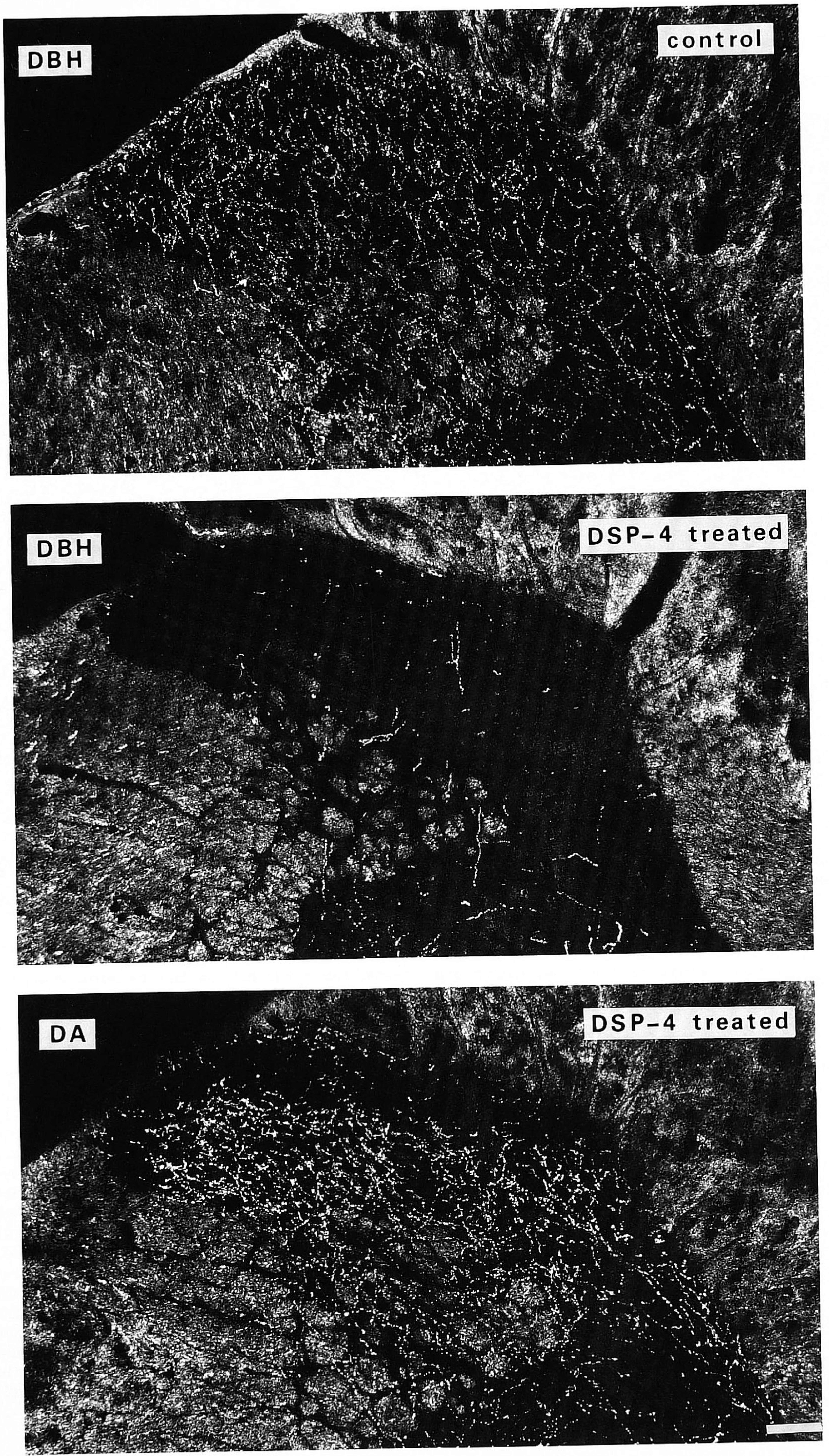

Figure 10 


\section{Location of the descending dopamine fibers}

In all animals most of the descending DA fibers were located in the dorsolateral funiculus (Figs. 1-6) and, to a limited extent, in the lateral and ventrolateral funiculi at cervical levels. An occasional fiber was seen in the ventromedial and dorsal funiculi. In sagittal and horizontal sections it was found that the funicular fibers showed few varicosities and appeared as relatively straight structures. Occasionally a fiber gave rise to a collateral, often at a right angle, which ran to the lateral part of the dorsal horn. Collateral fibers, which originated from stem fibers in the dorsolateral and lateral funiculi, were rarely seen to reach the ventral horn. Apart from the fibers in the funiculi there were also rostrocaudally oriented fibers in the dorsal horn, most notably in laminae I and III, but also in lamina II (Fig. 11). In the region around the central canal there were a large number of fibers, including several rostrocaudally oriented fibers. However, it appeared from sagittal and horizontal sections that these fibers form a minority and hence do not contribute significantly to the descending DA system.

\section{DSP-4 experiments}

Sections from the spinal cords of rats treated with DSP-4, which only affects the NA fibers in the dorsal horn (Jonsson, 1983), were processed for $\mathrm{DBH}$ immunocytochemistry (Fig. 10), and alternate sections from the same (DSP-4treated) rat were processed for DA immunocytochemistry (Fig. 10). In these DSP-4-treated rats there were very few DBH-immunoreactive fibers in the dorsal horn, but the ventral horn contained many $\mathrm{DBH}$-immunoreactive fibers. These results are similar to those described previously (Fritschy and Grzanna, 1989; Lyons et al., 1989). By contrast, the alternate sections showed many DA-immunoreactive fibers and varicosities throughout the spinal grey matter, including the dorsal horn, with the same pattern and intensity as in untreated rats. This demonstrated that the absence of (nor)adrenergic fibers, as visualized by the lack of DBH immunoreactivity, did not influence the DA immunoreactivity. Alternate sections from saline injected control rats, treated for DBH (Fig. 10) or DA immunocytochemistry as the DSP-4-treated rats, showed many immunoreactive fibers and varicosities throughout the dorsal and ventral horn in a similar pattern as found in the present study for DA or described elsewhere for DBH (Westlund et al., 1983; Fritschy and Grzanna, 1990; Rajaofetra et al., 1992b).

Fig. 10. Photomicrograph with darkfield illumination of the dorsal horn from the rat C7 segment. Top: Dopamine- $\beta$-hydroxylase (DBH)immunoreactive fibers and varicosities in a control (saline-injected) rat. Note that, in comparison with the DA labeling (bottom), the density of the $\mathrm{DBH}$ labeling is similar in all laminae of the dorsal horn (including lamina II) and the relatively fine caliber of the fibers. Middle: DBH immunoreactive fibers and varicosities two weeks after treatment with the neurotoxin DSP-4. Note that most DBH labeling has disappeared after DSP-4 treatment (compare with control animal in top micrograph). Bottom: DA-immunoreactive fibers and varicosities 2 weeks after treatment with the neurotoxin DSP-4 (same rat as in middle micrograph). Note that the DA immunoreactivity has not changed significantly in the absence of (nor)adrenaline (see middle micrograph), providing direct proof that the DA immunoreactivity is not located in (nor)adrenergic fibers and varicosities. Scale bar $=90 \mu \mathrm{m}$.

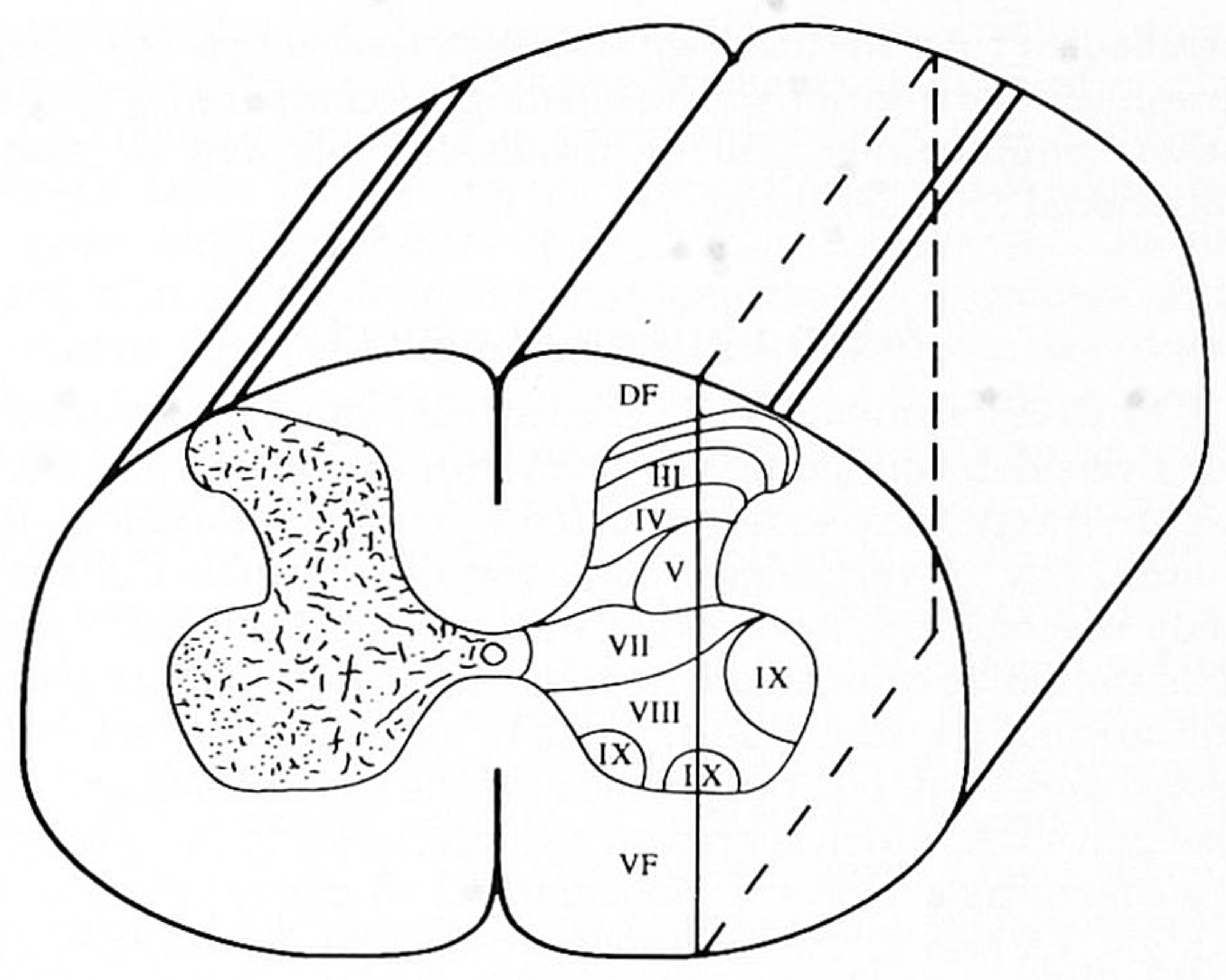

rostral caudal

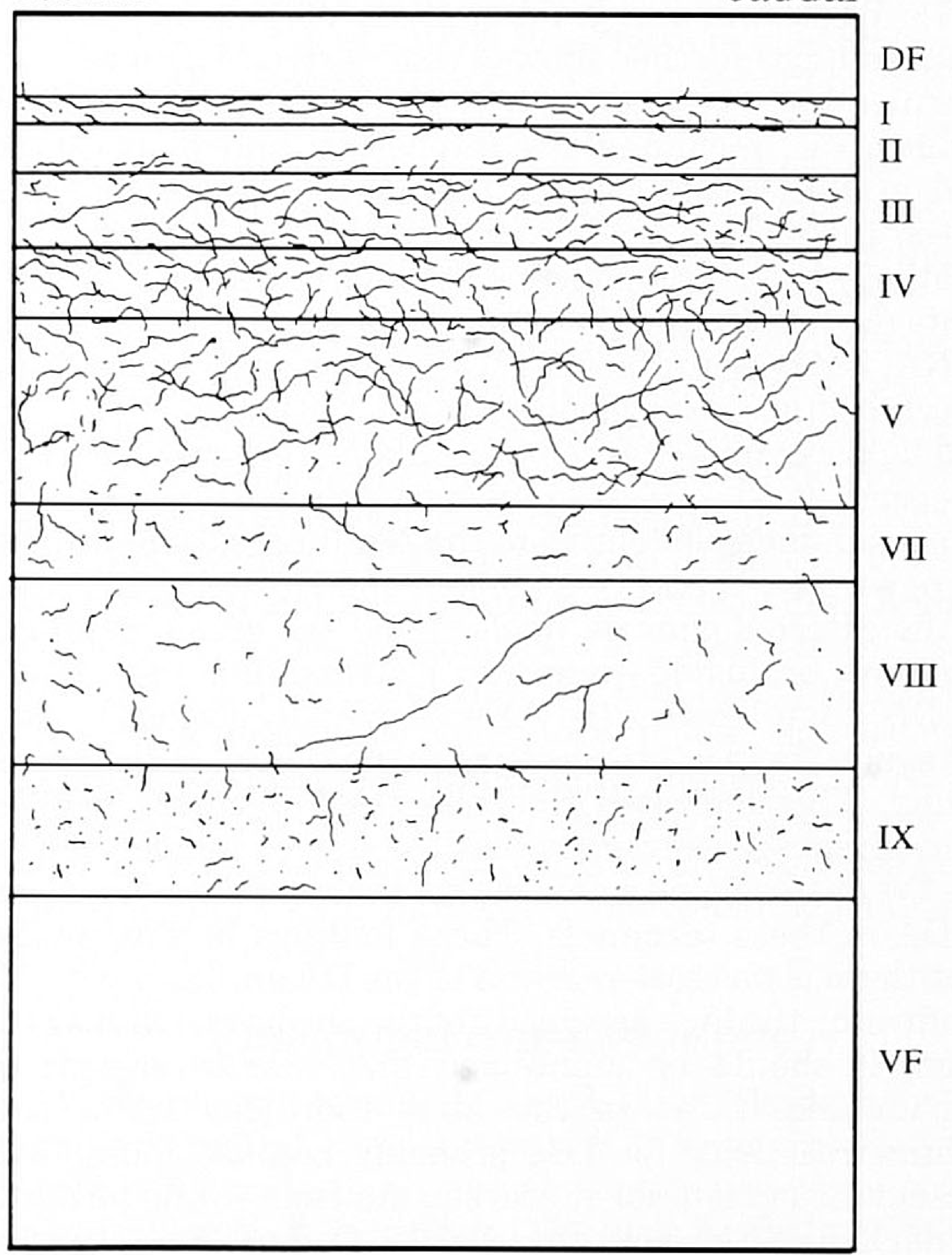

Fig. 11. Schematic drawings of the DA labeling in the rat low cervical spinal cord. Top: Three-dimensional drawing of the low cervical spinal cord. On the left the labeling is as it appears in a transverse section, on the right the plane of section of the drawing below is indicated. Bottom: Labeling in a sagittal section as indicated above. Note the rostrocaudally oriented fibers in laminae I-III, the more random orientation in lamina IV and especially lamina V, the paucity of labeling in laminae VII and VIII and the punctate labeling in lamina IX.

\section{DISCUSSION}

The present study shows the distribution of DA in the spinal cord of the rat, cat, and monkey. It provides a detailed study of all parts of the spinal cord, including the various specialized areas. Below the specificity of the DA 
antibodies that we used will be discussed. Then the topographical distribution of the labeling, as compared with the other monoamines, will be discussed, followed by some functional considerations.

\section{Methodological aspects}

The distribution of DA in the rat, cat, and monkey spinal cord was determined by using immunocytochemistry with highly specific antibodies directed against (glutaraldehydebound) DA. Nevertheless the possibility that the DA antibody reacted with adrenergic and/or noradrenergic terminals should be considered, not because of cross-reactivity of the antibodies (see below), which have been extensively tested and used, but rather because the DA antibodies may recognize DA, which is present as a precursor in (nor)adrenergic terminals. However, biochemical studies in areas with a high NA and a low DA innervation, like the cerebellum and hippocampus, have shown that the DA concentration is only $1-3 \%$ of the NA concentration (Commissiong et al., 1978; Westerink and Mulder, 1981; Verhage et al., 1992). These studies further showed that destruction of the locus coeruleus, and consequently the NA innervation of several brain areas, including the cerebellum and hippocampus, had no effect on DA levels in those areas (Westerink and De Vries, 1985). This would indicate that even in areas with a relatively high NA and a low DA concentration, DA represents the transmitter pool rather than the "precursor pool" of NA. Subsequent biochemical and/or anatomical studies in cerebellum (Panagopoulos et al., 1991; Ikai et al., 1992) and hippocampus (Verney et al., 1985; Verhage et al., 1992; Gasbarri et al., 1994) confirmed the existence of a DA projection independent from the NA innervation. Furthermore we have found (Van Dijken and Holstege, 1995) that in the external cuneate nucleus and the area postrema of the lower brainstem there was a strong immunoreactivity for $\mathrm{DBH}$, but labeling for DA was virtually absent (by using the same "Jannes" antibody as we have used in the present study). This indicated that the DA "precursor pool" in (nor)adrenergic terminals was too low to be identified by the DA antibody, probably due to a very high turnover rate of DA in these terminals. These findings further showed that there is no cross-reaction of the DA antibody with NA, confirming the high specificity of the antibody. On the other hand, it should be mentioned that (nor)adrenergic cell somata, like those in the locus coeruleus, show some immunoreactivity for DA, probably because more DA is present as a precursor in the somata than in the terminals of (nor)adrenergic neurons (see also Geffard et al., 1984).

Our control experiments for the spinal cord with DSP-4treated rats, in which $\mathrm{DBH}$ labeled (nor)adrenergic terminals in the dorsal horn had disappeared almost completely, showed that the DA immunoreactivity was still present in those rats. Moreover, the intensity and the pattern of the DA labeling were identical to those in untreated rats. A similar finding was obtained in a study (Mouchet et al., 1992) by using rats treated with 6-OHDA, which causes a specific degeneration of noradrenergic terminals, leaving the dopaminergic terminals largely unaffected. These experiments showed that in 6-OHDA-treated rats, DA-immunoreactive fibers were still present, although in other 6-OHDAtreated rats the NA immunoreactivity had disappeared. Taken together, the various data demonstrated that the DA antibody did not recognise DA in noradrenergic terminals, nor did it cross-react with NA.
It may be concluded that in the spinal cord, including the motoneuronal cell groups, a DA innervation is present, which is independent of the (nor)adrenergic innervation. Moreover, the DA labeling in the spinal cord as found in the present study represented exclusively DA fibers and terminals.

\section{Topographical distribution}

The results of the present study show that in rat, cat and monkey DA fibers and varicosities are present in all laminae of the spinal grey matter throughout the spinal cord, but with clear regional differences. The general pattern of labeling of the DA fibers and terminals is similar in the species investigated. DA labeled neuronal cell bodies were only found in the rostral $\mathrm{C} 1$ segment, probably representing the caudal extension of the medullary A1 and A2 cell groups. Although many neurons in the A1 and A2 cell group contain $\mathrm{DBH}$, some of them were found to be immunoreactive for dopamine (Maqbool et al., 1993) or TH (Mouchet et al., 1986) and not for DBH, indicating that they actually represented dopaminergic neurons. Labeled (neuronal) cell bodies were never identified below rostral $\mathrm{C} 1$, which is in contrast to the finding (Mouchet et al., 1986) of $\mathrm{TH}$ immunoreactive neurons at the $\mathrm{S} 1$ segment. If both observations were correct it must be assumed that these THlabeled cells are not able to convert L-dopa (the TH product) into dopamine, as has been shown to occur in the hypothalamus (Meister et al., 1988; Steinbusch et al., 1991).

Dorsal horn. In the dorsal horn, the lack of innervation of the substantia gelatinosa is the most conspicuous finding, which is consistent throughout all species, but least obvious in the cat. Previous studies in rat, by using immunocytochemistry with an antibody directed against DA (Yoshida and Tanaka, 1988; Mouchet et al., 1992; Ridet et al., 1992), have described the same pattern of innervation of the dorsal horn as in the present study. Similar to the distribution of DA, serotonin also showed a widespread innervation of the dorsal horn including a sparse innervation of the substantia gelatinosa, especially in its inner part. In rat (Marlier et al., 1991), cat (Ruda et al., 1982) and monkey (Kojima and Sano, 1983; LaMotte and Lanerolle, 1983) serotonin-immunoreactive labeling in the dorsal horn was found to be strongest in lamina I and outer lamina II, whereas there was only sparse labeling in the inner part of lamina II. Laminae III-VI were only moderately innervated. The distribution of the DA labeling in laminae III-V is slightly different from the serotonergic innervation since the DA labeling is stronger (rat) or similar (cat and monkey) as compared to the labeling in lamina I. An extensive innervation of the dorsal horn has also been described for NA- or DBH-immunoreactive fibers and terminals in the rat (Westlund et al., 1983; Fritschy and Grzanna, 1990; Hagihira et al., 1990; Rajaofetra et al., 1992b), cat (Doyle and Maxwell, 1991) and monkey (Westlund et al., 1984). The low innervation of lamina II, which is typical for DA and serotonin, is less obvious in case of $\mathrm{NA}$, although a stronger innervation of the outer part of lamina II versus the inner part has been suggested (Westlund et al., 1983; Hagihira et al., 1990; Rajaofetra et al., 1992b). Also in our study with $\mathrm{DBH}$, the difference between DA and NA with respect to the innervation of the substantia gelatinosa was very clear (cf. Fig. 10-top and bottom). In several areas the DA innervation of lamina I appeared as patches occasionally located outside the boundaries of this lamina. Whether these patches actually exceeded the border between lami- 
nae I and II or whether there was a local widening of lamina I, cannot be determined with certainty in the present material. The finding in one monkey of only sparse labeling in lamina II and deeper laminae, and lamina I was strongly labeled (Fig. 5-top), was rather surprising. This finding showed that regional density can vary, not only between, but also within species.

The intermediolateral cell column. The IML, which is located from caudal C8 to L3 (Strack et al., 1988), received a massive DA innervation and this was also true for the nuclei that may be considered as the medial extensions of the IML toward the central canal: the nucleus intercalatus and the central autonomic nucleus, located just dorsal and dorsolateral to the central canal. These findings are in agreement with previous reports on the DA innervation of the spinal cord (Skagerberg et al., 1982; Yoshida and Tanaka, 1988; Mouchet et al., 1992; Ridet et al., 1992). The IML is characterized by a patchy organization with dendritic bundles interconnecting the sympathetic subnuclei, forming a "ladderlike" pattern when viewed in horizontal sections (Romagnano and Hamill, 1984; Hosoya et al., 1991). The DA innervation exactly mimics this discontinuous organization, indicating that the DA fibers are aimed at the sympathetic preganglionic neurons and their dendrites. A similar "ladderlike" pattern of innervation was found with many other transmitters, including NA, serotonin, adrenaline, and various peptides like substance $\mathrm{P}$, oxytocin, vasopressin, neurotensin, somatostatin, neuropeptide $\mathrm{Y}$, and enkephalin (Swanson and McKellar, 1979; Glazer and Ross, 1980; Holets and Elde, 1982; Westlund et al., 1983; Romagnano and Hamill, 1984; Krukoff, 1987; Fuxe et al., 1990; Hosoya et al., 1991; Rajaofetra et al., 1992b).

The dorsal nucleus (column of Clarke). This nucleus is located in the same segments as the IML. It projects mainly to the cerebellum (Grant et al., 1982). In contrast to the IML, the dorsal nucleus received very few, if any, DAimmunoreactive fibers. The serotonergic innervation of the nucleus dorsalis is also low but not absent (Kojima et al., 1983a; Polistina et al., 1990). It is interesting to note that the central cervical nucleus, which also projects to the cerebellum (Matsushita and Hosoya, 1979), received a very sparse DA innervation as well. This might suggest that cerebellar-projecting neurons are avoided by the DA fibers. On the other hand, there are many more neurons, apart from the nucleus dorsalis and the central cervical nucleus, that project to the cerebellum (Grant et al., 1982). Since these cells are scattered over different locations in the spinal cord, it will be difficult to determine whether or not they receive a monoaminergic innervation. The reason for the avoidance by dopamine of spinal nuclei projecting to the cerebellum is still unclear.

The ventral horn. The presence of DA in the motoneuronal cell groups of the ventral horn was discovered much later than in the dorsal horn (Yoshida and Tanaka, 1988; Shirouzu et al., 1990; Ridet et al., 1992). The most conspicuous aspect of the DA labeling in the motoneuronal cell groups was its fine granular, punctate-like aspect, which was especially apparent in the rat. This appearance, that is probably caused by a large number of small, lightly stained terminals, may have been the reason why initially the existence of dopaminergic terminals in the ventral horn was denied or neglected. Also in our material, after a less than optimal fixation or immunocytochemical procedure, the DA labeling in the ventral horn was the first to disappear. Thus, sensitive techniques are necessary for the anatomical identification of dopaminergic terminals in the ventral horn, which is in line with the biochemical observation that the DA concentration in the ventral horn is significantly lower than in the dorsal horn (Fleetwood-Walker and Coote, 1981; Basbaum et al., 1987). Apparently, the fine granular network in the motoneuronal cell groups of the ventral horn is derived mostly from fibers in the dorsal horn, which are running through the intermediate zone to reach the motoneuronal area. Other monoaminergic transmitters, like serotonin and NA, have also been reported to show a finer appearance in the motoneuronal cell groups than in the dorsal horn (Kojima et al., 1983a; Fritschy et al., 1987). The strongest labeling in the motoneuronal cell groups was found in the cremaster nucleus, situated ventromedially at rostral lumbar levels, and in Onuf's nucleus (in cat and monkey) and its homologue in the rat (see the Results section) at the lumbosacral level. These sexually dimorphic nuclei also receive a strong innervation of serotonin, NA and various peptides (Kojima et al., 1983b, 1985; Kojima and Sano, 1984; Nagy and Senba, 1985; Uda et al., 1986; Newton and Hamill, 1988; Wang et al., 1989; Newton, 1990; Poulat et al., 1992; Rajaofetra et al., 1992a). We are presently investigating the DA innervation of these nuclei in more detail, especially with respect to possible differences in innervation between males and females.

DA and glutamate. In most parts of the spinal cord, the distribution of the DA immunoreactivity is very similar to the distribution of NA and serotonin. In this respect it is interesting to note that immunoreactivity for glutamate or glutaminase (a glutamate synthesizing enzyme) was present in serotonergic neurons of the raphe nuclei (Kaneko et al., 1990; Nicholas et al., 1992; see also Holstege, 1996) and noradrenergic neurons in the locus coeruleus area (Kaneko et al., 1990; Fung et al., 1994; Liu et al., 1995), all of which give rise to descending spinal projections. These findings suggest an extensive colocalization of glutamate with serotonin and with NA. In view of the many similarities between the different monoamines, it may be speculated that the dopaminergic terminals in the spinal cord also contain glutamate, as was also suggested by the presence of glutaminase in dopaminergic neurons in the A11 cell group (Kaneko et al., 1990) from which the spinal dopaminergic terminals originate.

\section{Functional considerations}

DA fibers and terminals are located throughout the spinal grey matter. Consequently it is to be expected that DA will influence both sensory and motor systems as well as various autonomic functions. Below the effects of DA on some major spinal cord functions, and the receptors involved, will be discussed.

DA effects on sensory transmission. Initially the effects of DA on sensory processing of peripheral sensory information in the spinal cord were studied by measuring the latencies of several (spinal) reflexes, like the hot-plate and tail-flick reflexes, following application of DA and various DA agonists (Barasi et al., 1987; reviewed in Jensen, 1986) . These studies generally showed an increase in latency, suggesting an inhibition of sensory (pain) transmission. In most cases these effects could be reversed by dopamine D2 receptor (D2) antagonists. However, effects on spinal reflexes may also be produced by influencing the motor component of the reflex. This problem does not occur with direct recordings from spinothalamic tract neurons in the superficial or deep dorsal horn. These studies showed that 
in monkey (Willcockson et al., 1984) DA decreased the response of dorsal horn cells to glutamate and to noxious pinch. In rat and cat (Fleetwood-Walker et al., 1988) DA or a D2 agonist, iontophoretically applied to dorsal horn neurons, selectively inhibited the responses of these neurons to noxious stimuli, although the responses to nonnociceptive stimuli were unaffected. The same results were obtained after stimulating the A11 DA cell group, from where the DA spinal projections originate. All these effects were reversed by a D2 receptor antagonist. More recently, evidence was found that spinal DA is involved in the antinociceptive effects of morphine (Weil-Fugazza and Godefroy, 1991) and cocaine (Kiritsy-Roy et al., 1994). These effects could also be antagonized by D2 antagonists. However, the exact mechanisms involved are still unclear.

All the above studies indicate a prominent role of D2 receptors in mediating the antinociceptive effects of DA. This is in agreement with ligand binding studies on DA receptors in the spinal cord that show the existence of D2 receptors in the dorsal horn (for details and references see Van Dijken et al., 1996). Furthermore, recent in situ hybridization and immunocytochemical studies on the localization of spinal D2 receptors in our laboratory (Van Dijken et al., 1996) have also shown the existence of neurons in the dorsal horn, including lamina I, expressing D2 receptors. Taken together, the various data indicate that DA exerts an inhibitory effect on nociceptive transmission in the spinal dorsal horn, mediated by D2 receptors, but the effects on nonnociceptive transmission and the involvement of D1 receptors may be less prominent.

DA effects on motor control. At present only a few studies have investigated the effects of DA on spinal motor output. In an early study in cat (Barasi and Roberts, 1977), an increase in the field potential of antidromically activated motoneurons was found, after iontophoretic application of DA in the motoneuronal cell groups. This effect was blocked by a (nonspecific) DA receptor antagonist. These results suggested that DA produced an increase in motoneuron excitability. This effect may be accomplished by enhancing glutamate activated currents, as shown in cultured embryonic chick motoneurons (Smith et al., 1995). A similar mechanism, that is, the facilitation of motoneuronal excitation by other transmitters, like glutamate, has also been proposed for serotonin and noradrenalin (White and Neuman, 1980; White, 1985). Other studies have investigated the effect of DA or DA receptor agonists and antagonists on various monosynaptic and polysynaptic spinal reflexes with contradictory results. In some cases, facilitation was found (Dupelj and Geber, 1981), but other workers reported an inhibitory effect (Carp and Anderson, 1982; Ono and Fukuda, 1984; Pehek et al., 1989). In addition, it was found in spinal rats (Maitra et al., 1993) that intravenously applied apomorphine, a nonselective DA receptor agonist, had an inhibitory influence on Renshaw cell bursts elicited by electrical stimulation of the ventral roots, but a similar concentration of apomorphine had no effect on the monosynaptic reflex from the dorsal root. A recent study on the monosynaptic reflex in acutely spinalized rats-by using various DA agonists and antagonists like apomorphine and bromocriptine (a D2 agonist) (Kamijo et al., 1993)—showed a depression of this reflex, which was mediated by neither D1 nor D2 receptors.

In a separate line of experiments, mostly performed in the late sixties (reviewed in Grillner, 1975) the effects of 3,4-dihydroxyphenylalanine (DOPA) were investigated. An intravenous injection of DOPA produced walking on a treadmill in the spinal cat and had powerful, but complicated, effects on various other reflexes (Andén et al., 1966b; Commissiong and Sedgwick, 1974; Grillner, 1975). Since DOPA is a precursor in the DA and NA synthesis and active only after decarboxylation (Andén et al., 1966a), it was generally assumed that the synthesis of DA from DOPA and the subsequent formation and release of NA, were responsible for the effects of DOPA in the spinal cord. This assumption was based on pharmacological experiments (Jurna and Lundberg, 1968) and the supposition that DA was present only as a precursor for NA (see the introductory section of this article). However, there are indications that DA may also play a role in mediating the effects of DOPA (Carp et al., 1989). A recent study (Skoog and Noga, 1995) in cat and guinea pig on the effects of iontophoretically applied DA on group II afferent fibers showed a significant depression of the monosynaptic field potential of electrically stimulated group II fibers, but there was no effect on group I fibers. It was further suggested that the effects in the dorsal horn were mediated by D1 as well as D2 receptors, and those in the intermediate zone were not mediated by DA receptors. This latter finding would fit with the low amount of DA that we have found in the intermediate zone. The strong innervation of the sexually dimorphic nuclei in the spinal cord suggests a specific function of DA in this special group of motoneurons. The finding (Van Dijken et al., 1996) that D2 receptors were present in the (the homologue of) Onuf's nucleus in the rat would strengthen this idea, although the specific function of DA in these cases is unclear. Taken together it may be concluded that the effects of DA on motor output are diverse and exerted on the motoneuronal as well as on the interneuronal level. It seems likely that different types of DA receptors are involved, but some effects may be produced by non-DA receptors. Also a presynaptic action should not be excluded (Maitra et al., 1993). More detailed analyses of the effects of DA on individual (moto)neurons, rather than on groups of cells or on reflexes, are needed to broaden our understanding of the effects of DA on the motor system, and to compare the cellular physiology of DA with the actions of NA and serotonin (reviewed in White et al., 1996). In view of the presence of DA in the motoneuronal cell groups the question arises whether part of the disturbed motor performance in Parkinson disease may be attributed to changes in DA neurotransmission at the spinal level (Lindvall et al., 1983). However, there is no evidence that A11 dopaminergic neurons are affected in Parkinson disease and in addition it was shown (Scatton et al., 1986) that the DA concentration in the spinal cord of parkinsonian patients was the same as compared to healthy subjects. Therefore, it seems at present unlikely that changes in spinal DA are involved in producing the motor deficits associated with Parkinson disease.

DA effects on autonomic functions. The dense DA innervation of the preganglionic neurons in the IML, suggests that DA is strongly involved in regulating the sympathetic outflow. Studies on the effects of DA have focussed mainly on blood pressure and heart rate, which are controlled by the preganglionic sympathetic neurons in the upper thoracic area (Lahlou et al., 1990). Intrathecal administration of D1 and D2 receptor agonists showed that hypotensive effects could be obtained after D1 and also after D2 receptor activation, although bradycardia was related only to D2 receptor activation (Pellissier and Demenge, 
1991). Our recent study (Van Dijken et al., 1996) by using in situ hybridization and immunocytochemistry also showed the presence of D2 receptors in the IML. Iontophoretic application of DA onto a very limited number of preganglionic sympathetic neurons at the Th- 2 segment induced an increase in firing rate of these neurons (Lewis and Coote, 1990), suggesting an increase in blood pressure and heart rate. However, it was shown in the same study that the effects of NA, which were investigated in much more detail than those of DA, were inhibitory in high doses and excitatory in low doses. If the same mechanism also applies to the effects of dopamine, it may explain that the effects of DA on the sympathetic preganglionic neurons regulating blood pressure and heart rate, are not straightforward. The effects of dopamine may depend not only on the types of receptors that are involved, but also on the concentration of the transmitter released and on the interaction with many other transmitters that are present in the IML.

The DA innervation of the sacral cord suggests a specific innervation of the preganglionic parasympathetic neurons, although this innervation is much less pronounced than the innervation of the sympathetic preganglionic neurons in the IML. With respect to the effects of DA on the parasympathetic nuclei there are no data available. The high degree of collateralization in the DA diencephalospinal projection would imply that dopamine is released simultaneously in many different areas of the spinal cord, including the sympathetic and parasympathetic preganglionic neurons. If the release of DA is part of a specific type of behaviour, it is to be expected that DA will exert opposing effects on sympathetic and parasympathetic preganglionic neurons. Whether this is indeed the case is presently unclear.

\section{CONCLUSION}

This study shows the existence of a distinct and extensive DA innervation of the sensory, motor, and autonomic areas of the spinal cord of the rat, cat and monkey. Although the concentration of DA in the spinal cord is much less than that of NA and serotonin, evidence is now accumulating for specific effects of DA in these spinal cord areas, i.e. an inhibitory effect on sensory transmission, a mainly facilitory (but probably mixed) effect on motor transmission and a complicated, probably mainly inhibitory, effect on sympathetic outflow. However, more detailed studies are needed to determine the effects of DA in specific areas of the spinal cord with more certainty. The distributions of DA, NA, and serotonin are very similar, which strengthens the idea that the monoamines have a similar mode of operation and may have similar effects, although their activity may be regulated differently, depending on the behavioural context.

This study emphasizes that besides NA and serotonin, DA should also be included when considering the monoaminergic effects on spinal processing. In fact, the interaction between the various monoamines may be of even greater importance than the effect of the respective transmitters alone. Investigations along this line may prove worthwhile.

\section{ACKNOWLEDGMENTS}

We thank Dr. J. Voogd for reading the manuscript and Mr. E. Dalm for his help with the photography. This work was supported by grant 900-550-072 from the Netherlands Research Organization ( NWO).

\section{LITERATURE CITED}

Andén, N.-E., M.G.M. Jukes, and A. Lundberg (1966a) The effect of DOPA on the spinal cord. 2. A pharmacological analysis. Acta Physiol. Scand. 67:387-397.

Andén, N.-E., M.G.M. Jukes, A. Lundberg, and L. Vyklicky (1966b) The effect of DOPA on the spinal cord. 1. Influence on transmission from primary afferents. Acta Physiol. Scand. 67:373-386.

Barasi, S., and M.H.T. Roberts (1977) Responses of motoneurons to electrophoretically applied dopamine. Br. J. Pharmacol. 60:29-34.

Barasi, S., M.M. Ben-Sreti, A.L. Clatworthy, K.N. Duggal, J.P. Gonzalez, J. Robertson, K.F. Rooney, and R.D.E. Sewell (1987) Dopamine receptormediated spinal antinociception in the normal and haloperidol pretreated rat: Effects of sulpiride and SCH 23390. Br. J. Pharmacol. $90: 15-22$.

Basbaum, A.I., F. Godefroy, and J. Weil-Fugazza (1987) A new microdissection technique for regional biochemical analysis of the rat spinal cord: Serotonin, norepinephrine, dopamine and uric acid. Brain Res. 419:229238.

Björklund, A., and G. Skagerberg (1979) Evidence for a major spinal cord projection from the diencephalic A11 dopamine cell group in the rat using transmitter-specific fluorescent retrograde tracing. Brain Res. 177:170-175.

Blaschko, H. (1939) The specific action of L-Dopa decarboxylase. J. Physiol. 96:50-51.

Blessing, W.W., and J.P. Chalmers (1979) Direct projection of catecholamine (presumably dopamine)-containing neurons from hypothalamus to spinal cord. Neurosci. Lett. 11:35-40.

Buijs, R.M., M. Geffard, C.W. Pool, and E.M.D. Hoorneman (1984) The dopaminergic innervation of the supraoptic and paraventricular nucleus. Brain Res. 323:65-72.

Buijs, R.M., C.W. Pool, J.J. Van Heerikhuize, A.A. Sluiter, P.J. Van der Sluis, M. Ramkema, T.P. Van der Woude, and E. Van der Beek (1989) Antibodies to small transmitter molecules and peptides: Production and application of antibodies to dopamine, serotonin, GABA, vasopressin, vasoactive intestinal peptide, neuropeptide $\mathrm{Y}$, somatostatin and substance P. Biomed. Res. 10(Suppl. 3):213-221.

Carlsson, A. (1959) The occurrence, distribution and physiological role of catecholamines in the nervous system. Pharm. Rev. 11:490-493.

Carp, J.S., and R.J. Anderson (1982) Dopamine receptor-mediated depression of spinal monosynaptic transmission. Brain Res. 242:247-254.

Carp, J.S., Y. Ohno, and J.E. Warnick (1989) Prevention of phencyclidineinduced depression of the segmental reflex by L-3,4-dihydroxyphenylalanine in the rat spinal cord in vitro. J. Pharmacol. Exp. Ther. 248:10481053.

Commissiong, J.W., and E.M. Sedgwick (1974) A pharmacological study of the adrenergic mechanisms involved in the stretch reflex of the decerebrate rat. Br. J. Pharmacol. 50:365374.

Commissiong, J.W., C.L. Galli, and N.H. Neff (1978) Differentiation of dopaminergic and noradrenergic neurons in rat spinal cord. J. Neurochem. 30:1095-1099.

Dahlström, A., and K. Fuxe (1964) Evidence for the existence of monoaminecontaining neurons in the central nervous system. I. Demonstration of monoamines in the cell bodies of brain stem neurons. Acta Physiol. Scand. Suppl. 232:5-55.

Dietl, M., M. Arluison, P. Mouchet, C. Feuerstein, M. Manier, and J. Thibault (1985) Immunohistochemical demonstration of catecholaminergic cell bodies in the spinal cord of the rat. Histochemistry 82:385-389.

Doyle, C.A., and D.J. Maxwell (1991) Ultrastructural analysis of noradrenergic nerve terminals in the cat lumbosacral spinal dorsal horn: A dopamine- $\beta$-hydroxylase immunocytochemical study. Brain Res. 563:329333

Dupelj, M., and J. Geber (1981) Dopamine as a possible neurotransmitter in the spinal cord. Neuropharmacology 20:145-148.

Fleetwood-Walker, S.M., and J.H. Coote (1981) Contribution of noradrenaline-, dopamine- and adrenaline-containing axons to the innervation of different regions of the spinal cord of the cat. Brain Res. 206:95-106.

Fleetwood-Walker, S.M., P.J. Hope, and R. Mitchell (1988) Antinociceptive actions of descending dopaminergic tracts on cat and rat dorsal horn somatosensory neurones. J. Physiol. 399:335-348.

Fritschy, J.-M., and R. Grzanna (1989) Immunohistochemical analysis of the neurotoxic effects of DSP-4 identifies two populations of noradrenergic axon terminals. Neuroscience 30:181-197.

Fritschy, J.-M., and R. Grzanna (1990) Demonstration of two separate descending noradrenergic pathways to the rat spinal cord: Evidence for 
an intragriseal trajectory of locus coeruleus axons in the superficial layers of the dorsal horn. J. Comp. Neurol. 291:553-582.

Fritschy, J.-M., W.E. Lyons, C.A. Mullen, B.E. Kosofsky, M.E. Molliver, and R. Grzanna (1987) Distribution of locus coeruleus axons in the rat spinal cord: A combined anterograde transport and immunohistochemical study. Brain Res. 437:176-180.

Fung, S.J., K. Reddy, R.H. Liu, Z. Wang, and C.D. Barnes (1994) Existence of glutamate in noradrenergic locus coeruleus neurons of rodents. Brain Res. Bull. 35:505-512.

Fuxe, K., B. Tinner, B. Bjelke, L.F. Agnati, A. Verhofstad, H.G.W. Steinbusch, M. Goldstein, and M. Kalia (1990) Monoaminergic and peptidergic innervation of the intermediolateral horn of the spinal cord. Eur. J. Neurosci. 2:430-450.

Gasbarri, A., C. Verney, R. Innocenzi, E. Campana, and C. Pacitti (1994 Mesolimbic dopaminergic neurons innervating the hippocampal formation in the rat: A combined retrograde tracing and immunohistochemical study. Brain Res. 668:71-79.

Geffard, M., R.M. Buijs, P. Seguela, C.W. Pool, and M. Le Moel (1984) First demonstration of highly specific and sensitive antibodies against dopamine. Brain Res. 294:161-165.

Geffard, M., S. Patel, J. Dulluc, and A.-M. Rock (1986) Specific detection of noradrenaline in the rat brain by using antibodies. Brain Res. 363:395400 .

Glazer, E.J., and L.L. Ross (1980) Localization of noradrenergic terminals in sympathetic preganglionic nuclei of the rat: Demonstration by immunocytochemical localization of dopamine- $\beta$-hydroxylase. Brain Res. 185:3949

Grant, G., B. Wiksten, K.J. Berkley, and H. Aldskogius (1982) The location of cerebellar-projecting neurons within the lumbosacral spinal cord in the cat: An anatomical study with HRP and retrograde chromatolysis. J. Comp. Neurol 204:336-348.

Grillner, S. (1975) Locomotion in vertebrates: Central mechanisms and reflex interaction. Physiol. Rev. 55:247-304

Hagihira, S., E. Senba, M. Yoshida, M. Tohyama, and I. Yoshiya (1990) Fine structure of noradrenergic terminals and their synapse in the rat spinal dorsal horn: An immunohistochemical study. Brain Res. 526:73-80.

Hedeman, L.S., M.K. Shellenberger, and J.H. Gordon (1974) Studies in experimental spinal cord trauma. Part I: Alterations in catecholamine levels. J. Neurosurg. 40:37-43.

Hökfelt, T., O. Phillipson, and M. Goldstein (1979) Evidence for a dopaminergic pathway in the rat descending from the A11 cell group to the spinal cord. Acta Physiol. Scand. 107:393-395.

Holets, V., and R. Elde (1982) The differential distribution and relationship of serotoninergic and peptidergic fibers to sympathoadrenal neurons in the intermediolateral cell column of the rat: A combined retrograde axonal transport and immunofluorescence study. Neuroscience 7:11551174 .

Holstege, J.C. (1996) The ventro-medial medullary projections to spinal motoneurons: Ultrastructure, transmitters and functional aspects. Prog. Brain Res. 107:159-181.

Hosoya, Y., N. Okado, Y. Sugiura, and K. Kohno (1991) Coincidence of "ladderlike patterns" in distributions of monoaminergic terminals and sympathetic preganglionic neurons in the rat spinal cord. Exp. Brain Res. 86:224-228.

Ikai, Y., M. Takada, Y. Shinonaga, and N. Mizuno (1992) Dopaminergic and non-dopaminergic neurons in the ventral tegmental area of the rat project, respectively, to the cerebellar cortex and deep cerebellar nuclei. Neuroscience 51:719-728.

Jensen, T.S. (1986) Endogenous antinociceptive systems: Studies on spinal and supraspinal modulating mechanisms with particular reference to monoaminergic and opioid systems. Acta Neurol. Scand. 74 Suppl. 108:6-34.

Jonsson, G. (1983) Chemical lesioning techniques: monoamine neurotoxins. Methods Chem. Neuroanat. 1:463-496.

Jurna, I., and A. Lundberg (1968) The influence of an inhibitor of dopaminebeta-hydroxylase on the effect of dopa on transmission in the spinal cord In C. von Euler, S. Skoglund, and U. Söderberg (eds.): Structure and function of inhibitory neuronal mechanisms, Wenner-Gren Cent.Int. Symp. Ser. 10:469-472.

Kamijo, N., T. Nagao, and H. Ono (1993) Depression of the monosynaptic reflex by apomorphine or bromocriptine is not mediated by D1/D2 receptors. Neuropharmacology 32:777-783.

Kaneko, T., H. Akiyama, I. Nagatsu, and N. Mizuno (1990) Immunohistochemical demonstration of glutaminase in catecholaminergic and serotoninergic neurons of rat brain. Brain Res. 507:151-154.
Karoum, F., J.C. Commissiong, N.H. Neff, and R.J. Wyatt (1981) Regional differences in catecholamines formation and metabolism in the rat spinal cord. Brain Res. 212:361-366.

Kiritsy-Roy, J.A., B.C. Shyu, P.J. Danneman, T.J. Morrow, C. Belczynsky, and K.L. Casey (1994) Spinal antinociception mediated by a cocainesensitive dopaminergic supraspinal mechanism. Brain Res. 644:109116.

Kojima, M., and Y. Sano (1983) The organization of serotonin fibers in the anterior column of the mammalian spinal cord. An immunohistochemical study. Anat. Embryol. 167:1-11.

Kojima, M., and Y. Sano (1984) Sexual differences in the topographical distribution of serotonergic fibers in the anterior column of the rat lumbar spinal cord. Anat. Embryol. 170:117-121.

Kojima, M., Y. Takeuchi, M. Goto, and Y. Sano (1983a) Immunohistochemical study on the localization of serotonin fibers and terminals in the spinal cord of the monkey (Macaca fuscata). Cell Tissue Res. 229:23-36.

Kojima, M., Y. Takeuchi, M. Kawata, and Y. Sano (1983b) Motoneurons innervating the cremaster muscle of the rat are characteristically densely innervated by serotonergic fibers as revealed by combined immunohistochemistry and retrograde fluorescent DAPI-labeling. Anat. Embryol. 168:41-49.

Kojima, M., T. Matsuura, A. Tanaka, T. Amagai, J. Imanishi, and Y. Sano (1985) Characteristic distribution of noradrenergic terminals on the anterior horn motoneurons innervating the perineal striated muscles in the rat. Anat. Embryol. 171:267-273.

Kondo, M., H. Fujiwara, and C. Tanaka (1985) Autoradiographic evidence for dopaminergic innervation in guinea pig spinal cord. Jap. J. Pharmacol. 38:442-444.

Krukoff, T.L. (1987) Peptidergic inputs to sympathetic preganglionic neurons. Can. J. Physiol. Pharmacol. 65:1619-1623.

Kuzuhara, S., and S.M. Chou (1980) Localization of the phrenic nucleus in the rat: A HRP study. Neurosci. Lett. 16:119-124.

Lahlou, S., P. Petitjean, G. Pellissier, P. Mouchet, C. Feuerstein, and P. Demenge (1990) Rostrocaudal localization of cardiovascular responses induced by intrathecal administration of apomorphine in conscious, freely moving rats. J. Cardiovasc. Pharmacol. 16:331-337.

LaMotte, C.C., and N.C. Lanerolle (1983) Ultrastructure of chemically defined neuron systems in the dorsal horn of the monkey. III. Serotonin immunoreactivity. Brain Res. 274:65-77.

Lewis, D.I., and J.H. Coote (1990) Excitation and inhibition of rat sympathetic preganglionic neurones by catecholamines. Brain Res. 530:229234.

Lindvall, O., A. Björklund, and G. Skagerberg (1983) Dopaminecontaining neurons in the spinal cord: Anatomy and some functional aspects. Ann. Neurol. 14:255-260.

Liu, R.-H., S.J. Fung, V.K. Reddy, and C.D. Barnes (1995) Localization of glutamatergic neurons in the dorsolateral pontine tegmentum projection to the spinal cord of the cat with a proposed role of glutamate on lumbar motoneuron activity. Neuroscience 64:193-208.

Lyons, W.E., J.-M. Fritschy, and R. Grzanna (1989) The noradrenergic neurotoxin DSP-4 eliminates the coeruleospinal projection but spares projections of the A5 and A7 groups to the ventral horn of the rat spinal cord. J. Neurosci. 9:1481-1489.

Magnusson, T. (1973) Effect of chronic transection on dopamine, noradrenaline and 5-hydroxytryptamine in the rat spinal cord. Naunyn-Schmiedebergs Arch. Pharmacol. 278:13-22.

Maitra, K.K., P. Seth, M. Thewissen, and H.-G. Ross (1993) Dopaminergic influence on the excitability of antidromically activated Renshaw cells in the lumbar spinal cord of the rat. Acta Physiol. Scand. 148:101-107.

Maqbool, A., T.F.C. Batten, P.A. Berry, and P.N. McWilliam (1993) Distribution of dopamine-containing neurons and fibres in the feline medulla oblongata: A comparative study using catecholamine-synthesizing enzyme and dopamine immunocytochemistry. Neuroscience 53:717-733.

Marlier, L., F. Sandillon, P. Poulat, N. Rajaofetra, M. Geffard, and A. Privat (1991) Serotonergic innervation of the dorsal horn of rat spinal cord: Light and electron microscopic immunocytochemical study. J. Neurocytol. 20:310-322.

Matsushita, M., and Y. Hosoya (1979) Cells of origin of the spinocerebellar tract in the rat, studied with the method of retrograde transport of horseradish peroxidase. Brain Res. 173:185-200.

Matsushita, M., and T. Ueyama (1973) Ventral motor nucleus of the cervical enlargement in some mammals: Its specific afferents from the lower cord levels and cytoarchitecture. J. Comp. Neurol. 150:33-52.

McKenna, K.E., and I. Nadelhaft (1986) The organization of the pudendal nerve in the male and female rat. J. Comp. Neurol. 248:532-549. 
Meister, B., T. Hökfelt, H.W.M. Steinbusch, G. Skagerberg, O. Lindvall, M. Geffard, T.H. Joh, A.C. Cuello, and M. Goldstein (1988) Do tyrosine hydroxylase-immunoreactive neurons in the ventrolateral arcuate nucleus produce dopamine or only L-DOPA. J. Chem. Neuroanat. 1:59-64.

Montagu, K.A. (1957) Catechol compounds in rat tissues and in brains of different animals. Nature 180:244-245.

Mouchet, P., B. Guerin, and C. Feuerstein (1982) Dissociate destruction of noradrenaline and dopamine descending projections in the thoracic spinal cord of the rat. Life Sci. 30:373-381.

Mouchet, P., M. Manier, M. Dietl, C. Feuerstein, A. Berod, M. Arluison, L. Denoroy, and J. Thibault (1986) Immunohistochemical study of catecholaminergic cell bodies in the rat spinal cord. Brain Res. Bull. 16:341-353.

Mouchet, P., M. Manier, and C. Feuerstein (1992) Immunohistochemical study of the catecholaminergic innervation of the spinal cord of the rat using specific antibodies against dopamine and noradrenaline. J. Chem. Neuroanat. 5:427-440.

Nagy, J.I., and E. Senba (1985) Neural relations of cremaster motoneurons, spinal cord systems and the genitofemoral nerve in the rat. Brain Res. Bull. 15:609-627.

Nakagawa, S. (1980) Onuf's nucleus of the sacral cord in a South American monkey (Saimiri): Its location and bilateral cortical input from area 4 . Brain Res. 191:337-344

Newton, B.W. (1990) Peptidergic innervation of the cremaster nucleus I. A sexually dimorphic population of substance Pcontaining intraspinal neurons exists in the substance $\mathrm{P}$ pathway to the rat cremaster nucleus. Brain Res. 537:187-196.

Newton, B.W., and W. Hamill (1988) Neuropeptide Y immunoreactivity is preferentially located in rat lumbar sexually dimorphic nuclei. Neurosci. Lett 94:10-16.

Nicholas, A.P., V.A. Pieribone, U. Arvidsson, and T. Hökfelt (1992) Serotonin-, substance P- and glutamate/aspartatelike immunoreactivities in medullo-spinal pathways of rat and primate. Neuroscience 48:545-559.

Ono, H., and H. Fukuda (1984) Effect of methamphetamine on rat spinal cord. Neuropharmacology 23:637-642.

Panagopoulos, N.T., G.C. Papadopoulos, and N.A. Matsokis (1991) Dopaminergic innervation and binding in rat cerebellum. Neurosci. Lett. 130:208212.

Pehek, E.A., J.T. Thompson, and E.M. Hull (1989) The effects of intrathecal administration of the dopamine agonist apomorphine on penile reflexes and copulation in the male rat. Psychopharmacol. 99:304-308.

Pellissier, G., and P. Demenge (1991) Hypotensive and bradycardic effects elicited by spinal dopamine receptor stimulation: Effects of D1 and D2 receptor agonists and antagonists. J. Cardiovasc. Pharmacol. 18:548555.

Polistina, D.C., M. Murray, and M.E. Goldberger (1990) Plasticity of dorsal root and descending serotoninergic projections after partial deafferentation of the adult rat spinal cord. J. Comp. Neurol. 299:349-363.

Poulat, P., F. Sandillon, L. Marlier, N. Rajaofetra, C. Oliver, and A. Privat (1992) Distribution of thyrotropin-releasing hormone in the rat spinal cord with special reference to sympathetic nuclei: A light- and electronmicroscopic immunocytochemical study. J. Neurocytol. 21:157-170.

Rajaofetra, N., J.-G. Passagia, L. Marlier, P. Poulat, F. Pellas, F. Sandillon, B. Verschuere, D. Gouy, M. Geffard, and A. Privat (1992a) Serotonergic, noradrenergic and peptidergic innervation of Onuf's nucleus of normal and transected spinal cords of baboons (Papio papio). J. Comp. Neurol. 318:1-17.

Rajaofetra, N., J.-L. Ridet, P. Poulat, L. Marlier, F. Sandillon, M. Geffard, and A. Privat (1992b) Immunocytochemical mapping of noradrenergic projections to the rat spinal cord with an antiserum against noradrenaline. J. Neurocytol. 21:481-494.

Ridet, J.-L., F. Sandillon, N. Rajaofetra, M. Geffard, and A. Privat (1992) Spinal dopaminergic system of the rat: Light and electron microscopic study using an antiserum against dopamine, with particular emphasis on synaptic incidence. Brain Res. 598:233-241.

Romagnano, M.A., and R.W. Hamill (1984) Spinal sympathetic pathway: An enkephalin ladder. Science 225:737-739.

Ruda, M.A., J. Coffield, and H.W.M. Steinbusch (1982) Immunocytochemical analysis of serotonergic axons in laminae I and II of the lumbar spinal cord of the cat. J. Neurosci. 2:1660-1671.

Sato, M., N. Mizuno, and A. Konishi (1978) Localization of motoneurons innervating perineal muscles: A HRP study in cat. Brain Res. 140:149154.

Scatton, B., T. Dennis, R. L'Heureux, J.-C. Monfort, C. Duyckaerts, and F. Javoy-Agid (1986) Degeneration of noradrenergic and serotonergic but not dopaminergic neurones in the lumbar spinal cord of parkinsonian patients. Brain Res. 380:181-185.
Schrøder, H.D. (1980) Organization of the motoneurons innervating the pelvic muscles of the male rat. J. Comp. Neurol. 192:567-587.

Shirouzu, M., T. Anraku, Y. Iwashita, and M. Yoshida (1990) A new dopaminergic terminal plexus in the ventral horn of the rat spinal cord Immunohistochemical studies at the light and electron microscopical level. Experientia 46:201-204.

Skagerberg, G., and O. Lindvall (1985) Organization of diencephalic dopamine neurons projecting to the spinal cord in the rat. Brain Res. 342:340-351.

Skagerberg, G., A. Björklund, O. Lindvall, and R.H. Schmidt (1982) Origin and termination of the diencephalo-spinal dopamine system in the rat. Brain Res. Bull. 9:237-244.

Skagerberg, G., B. Meister, T. Hökfelt, O. Lindvall, M. Goldstein, T. Joh, and A.C. Cuello (1988) Studies on dopamine-, tyrosine hydroxylase- and aromatic L-amino acid decarboxylase-containing cells in the rat diencephalon: Comparison between formaldehyde-induced histofluorescence and immunofluorescence. Neuroscience 24:605-620.

Skoog, B., and B.R. Noga (1995) Dopaminergic control of transmission from group II muscle afferents to spinal neurones in the cat and guinea pig. Exp. Brain Res. 105:39-47.

Smith, D.O., D. Lowe, R. Temkin, P. Jensen, and H. Hatt (1995) Dopamine enhances glutamate-activated currents in spinal motoneurons. J. Neurosci. 15:3905-3912.

Steinbusch, H.W.M., and F.J.H. Tilders (1987) Immunohistochemical techniques for light-microscopical localization of dopamine, noradrenaline, adrenaline, serotonin and histamine in the central nervous system. In H.W.M. Steinbusch (ed.): Monoaminergic Neurons: Light Microscopy and Ultrastructure. Chichester: John Wiley, pp. 125-165.

Steinbusch, H.W.M., S.P. Van Vliet, J.G.J.M. Bol, and J. De Vente (1991) Development and application of antibodies to primary (DA, L-DOPA) and secondary (cGMP) messengers: A technical report. Neurocytochem. Methods NATO ASI Ser. H58:1-27.

Storm-Mathisen, J., A.K. Leknes, A.T. Bore, J.L. Vaaland, P. Edminson, F.H.S. Haug, and O.P. Otterson (1983) First visualization of glutamate and GABA in neurons by immunohistochemistry. Nature 301:517-520.

Strack, A.M., W.B. Sawyer, L.M. Marubio, and A.D. Loewy (1988) Spinal origin of sympathetic preganglionic neurons in the rat. Brain Res. 455:187-191.

Swanson, L.W., and B.K. Hartman (1975) The central adrenergic system: An immunofluorescence study of the location of cell bodies and their efferent connections in the rat utilizing dopamine- $\beta$-hydroxylase as a marker. J. Comp. Neurol. 163:467-506.

Swanson, L.W., and S. McKellar (1979) The distribution of oxytocin and neurophysin stained fibers in the spinal cord of the rat and monkey. J. Comp. Neurol. 188:87-106.

Swanson, L.W., P.E. Sawchenko, A. Berod, B.K. Hartman, K.B. Helle, and D.E. Vanorden (1981) An immunohistochemical study of the organization of catecholaminergic cells and terminal fields in the paraventricular and supraoptic nuclei of the hypothalamus. J. Comp. Neurol. 196:271285.

Uda, K., H. Okamura, F. Kawakami, and Y. Ibata (1986) Sexual differences in the distribution of substance $\mathrm{P}$ immunoreactive fibers in the ventral horn of the rat lumbar spinal cord. Neurosci. Lett. 64:157-162.

Ueyama, T., N. Mizuno, S. Nomura, A. Konishi, K. Itoh, and H. Arakawa (1984) Central distribution of afferent and efferent components of the pudendal nerve in cat. J. Comp. Neurol. 222:38-46.

Van Dijken, H., and J.C. Holstege (1995) Distribution of dopamine and dopamine- $\beta$-hydroxylase containing fibers and presumptive terminals in rat and monkey brain stem. Eur. J. Neurosci. Suppl. 8:197 (abstract).

Van Dijken, H., J. Dijk, P. Voorn, and J.C. Holstege (1996) Localization of dopamine $\mathrm{D} 2$ receptor in rat spinal cord identified with immunocytochemistry and in situ hybridization. Eur. J. Neurosci. 8:621-628.

Verhage, M., W.E.J.M. Ghijsen, F. Boomsma, and F.H. Lopes da Silva (1992) Endogenous noradrenaline and dopamine in nerve terminals of the hippocampus: Differences in levels and release kinetics. J. Neurochem. 59:881-887.

Verney, C., M. Baulac, B. Berger, C. Alvarez, A. Vigny, and K.B. Helle (1985) Morphological evidence for a dopaminergic terminal field in the hippocampal formation of young and adult rat. Neuroscience 14:1039-1052.

Voorn, P., and R.M. Buijs (1987) Ultrastructural demonstration of dopamine in the central nervous system. In H.W.M. Steinbusch (ed.): Monoaminergic Neurons: Light Microscopy and Ultrastructure. Chichester: John Wiley, pp. 241-264.

Wang, B.-R., E. Senba, and M. Tohyama (1989) Ultrastructural investigation of substance P-, leucine-enkephalin- and 5hydroxytryptamine-like 
immunoreactive terminals in the area of the cremaster motoneurons of the male rat. Neuroscience 28:711-723.

Weil-Fugazza, J., and F. Godefroy (1991) Further evidence for the involvement of the diencephalo-dopaminergic system in pain modulation: A neurochemical study on the effect of morphine in the arthritic rat. Int. J. Tissue React. 13:305-310.

Westerink, B.H.C., and J.B. De Vries (1985) On the origin of dopamine and its metabolite in predominantly noradrenergic innervated brain areas. Brain Res. 330:164-166.

Westerink, B.H.C., and T.B.A. Mulder (1981) Determination of picomole amounts of dopamine, noradrenaline, 3,4-dihydroxyphenylalanine, 3,4dihydroxyphenylacetic acid, homovanillic acid, and 5-hydroxyindolacetic acid in nervous tissue after one step purification on sephadex G-10, using high performance liquid chromatography with a novel type of electrochemical detection. J. Neurochem. 36:1449-1462.

Westlund, K.N., R.M. Bowker, M.G. Ziegler, and J.D. Coulter (1983) Noradrenergic projections to the spinal cord of the rat. Brain Res. 263:15-31
Westlund, K.N., R.M. Bowker, M.G. Ziegler, and J.D. Coulter (1984) Origins and terminations of descending noradrenergic projections to the spinal cord of monkey. Brain Res. 292:1-16.

White S.R (1985) A comparison of the effects of serotonin, substance P and thyrotropin-releasing hormone on excitability of rat spinal motoneurons in vivo. Brain Res. 335:63-70.

White, S.R., and R.S. Neuman (1980) Facilitation of spinal motoneuron excitability by 5 -hydroxytryptamine and noradrenaline. Brain Res. 188:119-127.

White, S.R., S.J. Fung, D.A. Jackson, and K.M. Imel (1996) Serotonin, norepinephrine and associated neuropeptides: Effects on somatic motoneuron excitability. Prog. Brain Res. 107:182-???(in press).

Willcockson, W.S., J.M. Chung, Y. Hori, K.H. Lee, and W.D. Willis (1984) Effects of iontophoretically released amino acids and amines on primate spinothalamic tract cells. J. Neurosci. 4:732-740.

Yoshida, M., and M. Tanaka (1988) Existence of new dopaminergic terminal plexus in the rat spinal cord: Assessment by immunohistochemistry using anti-dopamine serum. Neurosci. Lett. 94:5-9. 